\title{
Bismuth ferrite materials for solar cells: Current status and prospects
}

\author{
Guang Chen ${ }^{\mathrm{a}}$, Jian Chen ${ }^{\mathrm{a}}$, Weijie Pei ${ }^{\mathrm{a}}$, Yinmei Lu ${ }^{\mathrm{a}}$, Qingfeng Zhang ${ }^{\mathrm{a}, *}$, Qi Zhang ${ }^{\mathrm{b}}$, Yunbin He ${ }^{\mathrm{a}, *}$ \\ ${ }^{a}$ Key Lab of Ferro \& Piezoelectric Materials and Devices, Ministry of Education Key \\ Laboratory of Green Preparation and Application for Functional Materials, School of \\ Materials Science \& Engineering, Hubei University, Wuhan, 430062, China \\ ${ }^{\mathrm{b}}$ Department of Manufacturing and Materials, Cranfield University, Cranfield, Bedfordshire, \\ MK43 OAL, UK
}

\begin{abstract}
Different from classical semiconductor photovoltaic devices, for ferroelectric photovoltaic devices, the open-circuit voltage $(V \mathrm{oc})$ can be four and even more orders of magnitude larger than the band gap of the ferroelectric, and the built-in electric field arising from the remnant polarization of the ferroelectric is throughout the bulk region, which is good for obtaining giant power conversion efficiency. Among ferroelectric materials, $\mathrm{BiFeO}_{3}$ with remnant polarization of as high as $-100 \mu \mathrm{C} / \mathrm{cm}^{2}$ has the narrowest direct band gap $(-2.7 \mathrm{eV})$. These indicate that high power conversion efficiency may be obtained in $\mathrm{BiFeO}_{3}$-based photovoltaic devices. Also, some significant research results about photovoltaic effects of $\mathrm{BiFeO}_{3}$ materials have been recently acquired. In order to better promote the development of $\mathrm{BiFeO}_{3}$-based photovoltaic devices, in this paper, we present a comprehensive review on the latest research progress in photovoltaic effects of $\mathrm{BiFeO}_{3}$ materials with different kinds of topography, including bulk, thin film, and nanomaterials.
\end{abstract}

\section{Keywords:}

$\mathrm{BiFeO}_{3}$ materials

Narrow band gap

Large remnant polarization

Built-in electric field

Ferroelectric photovoltaic effect 


\section{Introduction}

With the increasing global energy crisis and environmental issues, the development of clean and sustainable energy has become a major issue that governments need to address urgently in the worldwide. Solar energy is one of the most important sources of renewable energy due to its clean, pollution free and wide distribution area $[1,2]$.

In the current solar cell market, the commercialized crystalline silicon solar panels have high and stable conversion efficiency ( $>26 \%)$ and thus occupy most of the market share, while, their manufacturing and installation costs are high $[1,3,4]$. In order to reduce the cost, the second and third generation semiconductor solar cells, such as thin film, amorphous silicon solar cells, dye-sensitized solar cells, quantum dot solar cells, organic solars, and organicinorganic hybrid perovskite solar cells have been recently given much attention [5-9]. Generally, the photovoltaic effect includes two basic processes: (1) generation of electron-hole (e-h) pairs by photons absorption, and (2) separation of photo-generated electrons and holes to form net electric current flow [10]. In conventional p-n junction semiconductor solar cells, photons with energy higher than the band gap value are absorbed to produce e- $\mathrm{h}$ pairs, and then the pairs are separated by the built-in electric field that exists only in the space-charge region inside the p-n junction [11-17]. Thus, these solar cells have the following drawbacks [18-20]: (1) the open-circuit voltage $(\mathrm{Voc})$ is limited by the band gap of the light- absorbing semiconductor; (2) the photo-generated electrons and holes can't be effectively separated, may resulting in small short-circuit current $\left(J_{\mathrm{sc}}\right)$; (3) their power conversion efficiency (PCE) is limited by the Shockley-Queisser limit, which prevents any single p-n junction solar cell from converting more than $33.7 \%$ of the incident light. However, completely different from traditional p-n junction photovoltaic effects, for ferroelectric (FE) photovoltaic effects, the 
photo-generated electron-hole pairs can be separated by the built-in electric field arising from the remnant polarization of the ferroelectric, as shown in Fig. 1 and thus, the $V_{o c}$ is not limited by the band gap of the ferroelectric material [21-26]. Besides, the remnant polarizationinduced built-in electric field is throughout the bulk region in ferroelectric, which is very helpful for the separation of electron-hole pairs, thus may result in large pho-tocurrent, and the photocurrent direction can be switched by changing the spontaneous polarization direction of the ferroelectric material [26]. All these provide a great potential for developing photovoltaic devices with high power conversion efficiencies and unique characteristics. Furthermore, ferroelectric materials are inexpensive, abundant, and stable, which is very beneficial to ferroelectric photovoltaic devices for the practical application [27,28].

To date, a great deal of work on the photovoltaic effect of ferro-electric materials (such as $\mathrm{BaTiO}_{3}, \mathrm{~Pb}(\mathrm{Zr}, \mathrm{Ti}) \mathrm{O}_{3}$, and $\left.\mathrm{Bi}_{4} \mathrm{Ti}_{3} \mathrm{O}_{12}\right)$ has been carried out [29-31]. However, the band gap of ferroelectric materials is usually large $(>3 \mathrm{eV})$, resulting in poor absorption for the visible light,

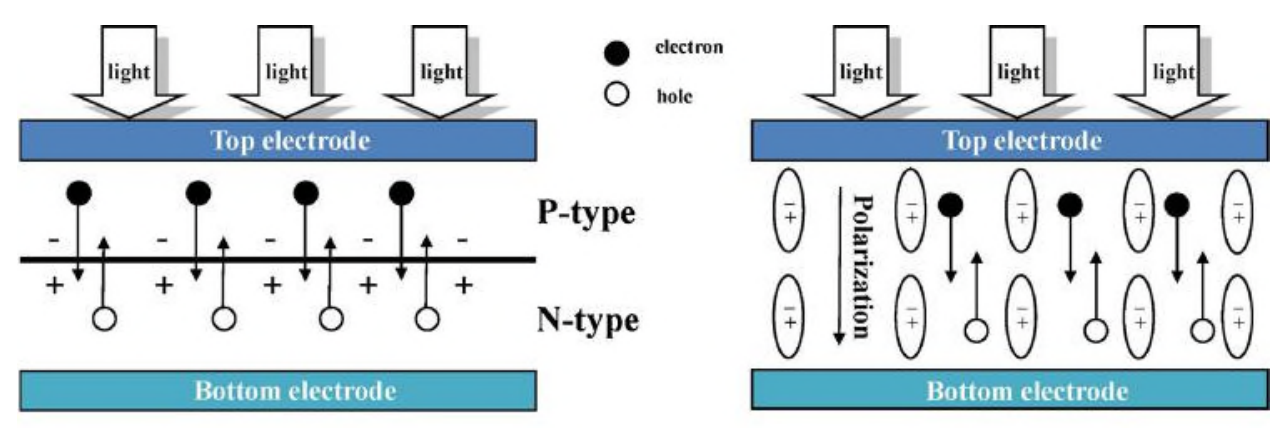

(a)

(b)

Fig. 1. Schematic illustration of the working principle of (a) p-n junction photovoltaic devices and (b) ferroelectric photovoltaic devices. 
and thus the power conversion efficiencies of ferroelectric photovoltaic devices have been still too low for practical applications. In general, common ferroelectric oxides with $\mathrm{ABO}_{3}$ type perovskite structure exhibit wide band gaps. This arises from the large difference in electronegativities of oxygen and the transition-metal atom at the B site [32]. At the same time, in most perovskite ferroelectric materials, the transition-metal ion at the B site also plays the crucial role of driving fer-roelectricity [33]. Any attempt to reduce the band gap by substitution of the B ion leads to a deterioration of ferroelectric properties [34]. Thus, in order to achieve ferroelectric photovoltaic devices with high conversion efficiency, it is urgent to develop new ferroelectric materials with both narrow band gap and large remnant polarization.

Currently, $\mathrm{BiFeO}_{3}(\mathrm{BFO})$ has attracted considerable interest due to its high temperature ferroelectric, and magnetic ordering and has been widely used in magneto-electric random access memory, sensor and actuator, ferroelectric tunneling junctions, non-volatile ferroelectric based random access memory, etc [35-39]. In very recent, some reports have indicated that $\mathrm{BiFeO}_{3}$ materials have not only large remnant polarization $\left(\sim 100 \mu \mathrm{C} / \mathrm{cm}^{2}\right)$ but also narrow band gap $(<2.7 \mathrm{eV})$ [40-46]. Thus, compared with $\mathrm{BaTiO}_{3}, \mathrm{~Pb}(\mathrm{Zr}, \mathrm{Ti}) \mathrm{O}_{3}$, and $\mathrm{Bi}_{4} \mathrm{Ti}_{3} \mathrm{O}_{12}$, etc. ferroelectrics, $\mathrm{BiFeO}_{3}$ materials are more suitable for developing fer-roelectric photovoltaic devices with high power conversion efficiency and much work on $\mathrm{BiFeO}_{3}$ photovoltaic effects has been reported [47-51]. However, no comprehensive review on the photovoltaic effect in $\mathrm{BiFeO}_{3}$-based materials has heretofore been presented.

In view of this, in this review, we review the recent progress about the photovoltaic effect of $\mathrm{BiFeO}_{3}$-based materials, including bulk, thin films and nanomaterials, which will be very helpful for developing new ferroelectric materials with both narrow band gap and large remnant 
polarization, and ferroelectric photovoltaic devices with high power conversion efficiency. In addition, we give some new strategies to optimize further $\mathrm{BiFeO}_{3}$-based photovoltaic devices.

\section{Properties of $\mathrm{BiFeO}_{3}$ related to photovoltaic effects}

\subsection{Crystal structure of $\mathrm{BiFeO}_{3}$}

$\mathrm{BiFeO}_{3}$ is known to be one of the most important material that exhibits multiferroic characteristic at room temperature. It is a rhombo-hedrally distorted ferroelectric perovskite $\left(T_{\mathrm{c}}=1103 \mathrm{~K}\right)$ with the space group $R 3 c$, as shown in Fig. 2(a), and shows G-type antiferromag-netism up to $643 \mathrm{~K}[52,53]$. The unit cell has a lattice parameter, $a \mathrm{rh}$, of $3.965 \AA$ and a rhombohedral angle, $\alpha$ rh, of ca. $89.3-89.48^{\circ}$ at room temperature with ferroelectric polarization along [111] pseudocubic direction [54]. The unit cell can also be described in a hexagonal frame of reference, with the hexagonal c-axis parallel to the diagonals of the perovskite cube, i.e., [001]hexagonal //[111] pseudocubic, as presented in Fig. 2(b) [52,54]. The hexagonal lattice parameters are $a_{\mathrm{hex}}=5.58 \AA$ and $c_{\mathrm{hex}}=13.90 \AA$ [54]. However, according to the recent research, the $\mathrm{BiFeO} 3$ thin films grown on various substrates show different crystal structures due to the interaction between the substrate and the film [55-58]. Since the ferroelectricity needs the off-center structural distortions in the lattice, the structural distortions in the $\mathrm{BiFeO} 3$ thin films may cause enhanced remnant polarization, which has also been recently confirmed by Yun et al. They prepared tetragonal $\mathrm{BiFeO} 3$ thin films with remnant polarization of $\sim 100 \mu \mathrm{C} / \mathrm{cm}^{2}$ on $\mathrm{Pt} / \mathrm{TiO}_{2} / \mathrm{SiO}_{2} / \mathrm{Si}$ substrates by pulsedlaser deposition, which lays a good foundation for developing ferroelectric photovoltaic devices with large open-circuit voltage [40]. 


\subsection{Optical properties of $\mathrm{BiFeO}_{3}$}

Recently, several research groups have investigated the optical band gap, photoconductivity, linear and non-linear optical properties of $\mathrm{BiFeO}_{3}$ materials, respectively $[46,59]$. Their experimental results showed that $\mathrm{BiFeO}_{3}$ is a semiconductor with a direct band gap of about 2.1-2.7 eV. Theoretically, Huang et al. investigated optical properties, including the frequency-dependent dielectric function, absorption coefficient, refractive index, extinction coefficient, and reflectivity of $\mathrm{BiFeO}_{3}$ materials by using density functional theory within generalized gradient approximation [60]. The calculated results indicated that $\mathrm{BiFeO}_{3}$ had an indirect (very close to direct) band gap of $1.06 \mathrm{eV}$, which was formed between the top of the $\mathrm{O} 2 \mathrm{p}$ valence band and the bottom of the Fe $3 \mathrm{~d}$ conduction band. Due to the strong hybridization between $\mathrm{Fe} 3 \mathrm{~d}$ and $\mathrm{O} 2 \mathrm{p}$ states, the electrical properties of $\mathrm{BiFeO}_{3}$ were considered to be determined by both the charge-transfer transitions from the occupied $\mathrm{O} 2 \mathrm{p}$ to unoccupied Fe $3 \mathrm{~d}$ states, and the d-d transition between the Fe $3 \mathrm{~d}$ valence and conduction bands. Besides, they thought although the direct band gap was reported for $\mathrm{BiFeO}_{3}$ in the form of bulk, film, nanowire and nanotube states, those experimental data also showed an absorption onset below the band gap energy, suggesting a weak optical transition. However, experimentally, the absorption was so weak that it could be ignored, and thus $\mathrm{BiFeO}_{3}$ was regarded by most researchers as having a direct band gap.

\section{Photovoltaic effects in BiFeO3-based materials}

Recently, the application of $\mathrm{BiFeO}_{3}$-based materials in solar cells has attracted much attention. In this section, we will discuss in detail photovoltaic effects of $\mathrm{BiFeO}_{3}$-based materials, including bulk, thin film, and nanomaterials. 


\subsection{Photovoltaic effects in $\mathrm{BiFeO}_{3}$-based bulk materials}

Hung et al. prepared $\mathrm{BiFeO}_{3}$ ceramics by using the solid-phase-reaction method and studied photovoltaic characteristics of $\mathrm{BiFeO}_{3}$ ceramic-based photovoltaic devices [61]. They found that the photovoltaic response of the devices made from this material depended strongly on light wavelength, light intensity, and sample thickness. The thinner sample had larger opencircuit photo-voltage and short-circuit photocurrent density, which was possibly because of fewer barriers in the conducting path. Besides, near-ultraviolet illumination at $\lambda=373 \mathrm{~nm}$ induced a much stronger photovoltaic response than that at $\lambda=532 \mathrm{~nm}$, which indicated that the photon energy at $\lambda=373 \mathrm{~nm}$ was more efficiently absorbed. Tu et al. used different metal elements to dope the $\mathrm{A}$ site of $\mathrm{BiFeO}_{3}$ and obtained better photovoltaic performance in comparison with pure $\mathrm{BiFeO} 3$ ceramic [62-65]. They first used calcium for A-site doping, and prepared (Bi0.95Ca0.05) FeO2.975 (BFO5C), $\left(\mathrm{Bi}_{0.90} \mathrm{Ca}_{0} 0.10\right) \mathrm{FeO}_{2.95}$ (BFO10C), and ${ }_{(\mathrm{Bi} 0.85 \mathrm{Ca} 0.15) \mathrm{FeO} 2.925}$ (BFO15C) ceramics by using the solid-state-reaction method to study their photovoltaic characteristics [62]. BFO10C ceramic devices exhibited a higher PCE than BFO5C and BFO15C, and the maximum PCE in $\mathrm{ITO} /\left(\mathrm{Bi}_{0.90} \mathrm{Ca}_{0} .10\right) \mathrm{FeO}_{2.95} / \mathrm{Au}$ device can reach $0.0072 \%$, which was larger than the maximum efficiency of $-0.002 \%$ in the ITO/BFO ceramic/Au devices [51]. The heterovalent substitution for $\mathrm{Bi}^{3+}$ with $\mathrm{Ca}^{2+}$ could lead to oxygen vacancies and an iron change of $\mathrm{Fe}^{3+} \rightarrow \mathrm{Fe}^{4+}$. Oxygen vacancies and the distribution of $\mathrm{Fe}^{3+}$ and $\mathrm{Fe}^{4+}$ ions in ceramics could affect the transport of charge carriers. All these factors caused the improvement of the PCE. Later, they introduced $\mathrm{Ba}^{2+}$ into $\mathrm{BiFeO}_{3}$ to replace $\mathrm{Bi}^{3+}$. The ITO/( $\left.\mathrm{Bi}_{1-x} \mathrm{Ba}_{x}\right) \mathrm{FeO}_{3-}$ $\delta / A u$ device exhibited obvious photovoltaic effects under illumination at $\lambda=405 \mathrm{~nm}$ [63]. The maximum $\mathrm{PCE}$ in $\mathrm{ITO} /\left(\mathrm{Bi}_{0.95} \mathrm{Ba}_{0.5}\right) \mathrm{FeO}_{2.95} / \mathrm{Au}$ device could reach $0.006 \%$ under illumination at 
$\lambda=405 \mathrm{~nm}$. Then, they used $\mathrm{Sr}^{2+}$ for A-site doping [64]. The maximal PCE of $0.004 \%$ was obtained in the ITO/ $\mathrm{Bi}_{0.95} \mathrm{Sr}_{0.05} \mathrm{FeO}_{2.975} / \mathrm{Au}$ device and the external quantum efficiency (EQE) was $0.2 \%$. They continued to use $\mathrm{Sm}^{3+}$ for A-site doping to prepare $\left(\mathrm{Bi}_{1-x} \mathrm{Sm}_{x}\right) \mathrm{FeO}_{3}(x=0.0$, $0.05,0.10)$ ceramics $(\mathrm{BFO} 100 \times \mathrm{Sm})$ based photovoltaic device and measured photovoltaic properties of the device under near-ultraviolet irradiation $(\lambda=405 \mathrm{~nm})$ [65]. The experimental results showed that BFO5Sm and BFO10Sm had smaller band gaps of 2.18 and $2.15 \mathrm{eV}$ than pure $\mathrm{BFO}\left(E_{\mathrm{g}}-2.24 \mathrm{eV}\right)$. The maximum PCE and EQE reached $0.37 \%$ and $4.1 \%$ in the ITO/BFO5Sm/ Au heterostructure devices, respectively. They thought the domain structures and hybridization between the $\mathrm{O} 2 p$ and $\mathrm{Fe} 3 d$ states play important roles for the enhanced photovoltaic response.

\subsection{Photovoltaic effects in $\mathrm{BiFeO}_{3}$-based thin films}

\subsubsection{Photovoltaic effects in pure $\mathrm{BiFeO}_{3}$-based thin films}

In $\mathrm{BiFeO} 3$ thin film-based solar cells, the annealing temperature, film thickness, polarization direction, Schottky barrier, strain, etc. all have obvious impacts on the photovoltaic performance. Liu et al. prepared $\mathrm{BiFeO}_{3}$ thin films by pulsed laser deposition at room temperature and studied the effect of the strain on the optical properties [66]. The compressively strained $\mathrm{BiFeO}_{3} / \mathrm{LaAlO}_{3}$ thin films had the largest band gap of about $3.12 \mathrm{eV}$, which red shifted to $2.75 \mathrm{eV}$ for the tensile-strained $\mathrm{BiFeO}_{3} / \mathrm{NdScO}_{3}$ thin films. The reduced band gap was beneficial to the absorption of the visible light and thus improved the photovoltaic effect. This research provided a good idea for designing $\mathrm{BiFeO}_{3}$-based solar cells with high PCE. Later, Chang et al. studied the photovoltaic property of sputter-deposited $\mathrm{BiFeO}_{3}$ polycrystalline films on $\mathrm{Pt} / \mathrm{Ti} / \mathrm{SiO}_{2} / \mathrm{Si}(100)$ substrates [67]. Fig. 3 showed the average 
short-circuit photocurrent density as a function of the illumination intensity. As shown in Fig. 3(a), upon increasing growth temperature $\left(T_{\mathrm{g}}\right)$ of the thin film, the short-circuit photocurrent density at a laser intensity of $220 \mathrm{~mW} / \mathrm{cm}^{2}$ increased from $5.1 \mu \mathrm{A} / \mathrm{cm}^{2}$ for $T_{\mathrm{g}}=350{ }^{\circ} \mathrm{C}$ to 11.7 $\mu \mathrm{A} / \mathrm{cm}^{2}$ for $T_{\mathrm{g}}=450{ }^{\circ} \mathrm{C}$, and then drastically decreased to $1 \mu \mathrm{A} / \mathrm{cm}^{2}$ for $T_{\mathrm{g}}=500 \square$. The sudden drop was attributed to the appearance of the secondary phase and the rougher surface. Similarly, as shown in Fig. 3(b), when the $\mathrm{BiFeO} 3$ thickness increased, the short-circuit pho-tocurrent density enhanced from $4.3 \mu \mathrm{A} / \mathrm{cm}^{2}$ for a thickness $t=50 \mathrm{~nm}$ to $14.2 \mu \mathrm{A} / \mathrm{cm}^{2}$ for $t=300 \mathrm{~nm}$, and then decreased to $8.2 \mu \mathrm{A} / \mathrm{cm}^{2}$ for $t=400 \mathrm{~nm}$. Biswas et al. prepared polycrystalline BiFeO3 film on Pt/ $\mathrm{Ti} / \mathrm{SiO}_{2} / \mathrm{Si}$ substrates and measured photovoltaic properties of the $\mathrm{Au} / \mathrm{BiFeO} / \mathrm{Pt}$ device [68]. When illuminated, the device exhibited a switchable photovoltaic effect under poled conditions. The measured photovoltaic effect revealed an open-circuit voltage of $0.47 \mathrm{~V}$ and a short-circuit current of $3.82 \mu \mathrm{A} / \mathrm{cm}^{2}$ under an illumination of $165 \mathrm{~mW} / \mathrm{cm}^{2}$. The open-circuit voltage and short-circuit current both changed upon changing the polarization direction, as shown in Fig. 4. These research results indicated the dominant role of the depolarization field rather than the interface in the photovoltaic characteristics of $\mathrm{BiFeO}_{3}$ film. Fang et al. fabricated $\mathrm{BiFeO}_{3}$ epitaxial films on $\mathrm{SrTiO}_{3}$ substrates with $\mathrm{La}_{0.7} \mathrm{Sr}_{0.3} \mathrm{MnO}_{3}$ (LSMO) and Pt as electrodes [69]. A more superior switchable photovoltaic response was obtained in the $\mathrm{Pt} / \mathrm{BiFeO}_{3} / \mathrm{La}_{0.7} \mathrm{Sr}_{0.3} \mathrm{MnO}_{3}$ device as compared with $\mathrm{La}_{0.7} \mathrm{Sr}_{0.3} \mathrm{MnO}_{3} / \mathrm{BiFeO}_{3} / \mathrm{La}_{0.7} \mathrm{Sr}_{0.3} \mathrm{MnO}_{3}$ device. To better understand how the interface affects the photovoltaic response, they turned to the energy diagram across the heterostructure (see Fig. 5). This suggested that the Schottky barrier modulation by ferroelectric polarization at the $\mathrm{Pt} / \mathrm{BiFeO}_{3}$ interface was mainly responsible for the photovoltaic effect, with a very small contribution from the bulk depolarization field. Peng et al. also suggested that photovoltaic effects were mainly dominated by the electrode/film interface. The modified interface state induced by the high- 
temperature thermal treatment was responsible for the photovoltaic effect of the investigated polycrystalline $\mathrm{BiFeO}_{3}$ thin-film capacitors [70]. The experimental results indicated that, not only the open-circuit voltage but also the short-circuit current density of the devices (600 and $750 \mathrm{~nm}$ thick) decreased with increasing annealing temperature at the top $\mathrm{Pt} / \mathrm{BiFeO}_{3}$ interfaces, as shown in Fig. 6. The maximum PCE at the room temperature for 600 - and 750 -nm-thick $\mathrm{BiFeO}_{3}$ thinfilm capacitors were $1.1 \times 10^{-2} \%$ and $2.3 \times 10^{-3} \%$, respectively. Yang et al. researched monodomain $\mathrm{BiFeO}_{3}$ thin films with only a single ferroelectric variant to exclude the influence of the domain walls [71]. Their experimental results showed that the bulk photovoltaic effect in Pt/ $\mathrm{BiFeO}_{3} / \mathrm{Pt}$ devices was an independent property characteristic of non-centrosymmetric structures rather than something that originates from the ferroelectric polarization. The direction of the photovoltaic current could be tuned by adjusting the incident light polarization and working temperature (see Fig. 7). Some results in the reports from Choi et al. and Kundys et al. also showed an angular dependence of the photocurrent on the light-polarization direction $[46,72]$. $\mathrm{BiFeO} 3$ thin films with different layers were deposited on $\mathrm{Pt} / \mathrm{Ti} / \mathrm{SiO}_{2} / \mathrm{Si}$ substrates via the solution-gelation method by Gao et al. to experimentally investigated how a nonuniform electric field formed by asymmetric electrodes affected the photovoltaic properties [28]. The $\mathrm{Au} / \mathrm{BiFeO}_{3} / \mathrm{Pt}$ heterostructures with 11 layers and asymmetric structures showed $1.3 \mathrm{~V}$ opencircuit voltages and $-0.242 \%$ power conversion efficiency when illuminated by sunlight (AM 1.5). Their experimental results revealed the importance of photovoltaic study in ferroelectric thin films by forming nonuniform electric fields. Kooriyattil et al. reported a remarkable photovoltaic effect in pulsed laser deposited multiferroic aurivillius phase $\mathrm{Bi}_{5} \mathrm{FeTi}_{3} \mathrm{O}_{15}$ thin films sandwiched between $\mathrm{ZnO}: \mathrm{Al}$ transparent conductive oxide top electrode and $\mathrm{SrRuO}_{3}$ bottom electrode fabricated on amorphous fused silica substrates [73]. Significant photovoltaic 
effects were observed in the device with $V_{\mathrm{oc}}$ of $-0.14 \mathrm{~V}$ and $J_{\mathrm{sc}}$ of about $10-16 \mu \mathrm{A} / \mathrm{cm}^{2}$. Besides, the photocurrent was found to be obviously dependent upon the polarization direction of the external electric field.

\subsubsection{Photovoltaic effects in doped $\mathrm{BiFeO}_{3}$ thin films}

To further improve the photovoltaic performance of $\mathrm{BiFeO}_{3}$-based materials, researchers prepared various doped $\mathrm{BiFeO}_{3}$ thin film-based photovoltaic devices. The doping serves to reduce the band gap of $\mathrm{BiFeO}_{3}$ materials and enhance the optical absorption ability. Gao et al. studied photovoltaic properties of La-substituted $\mathrm{BiFeO}_{3}$ films $[74,75]$. They grew $\mathrm{Bi}_{0.9} \mathrm{La}_{0.1} \mathrm{FeO}_{3}$ (BLFO) thin films on $\mathrm{La}_{0.7} \mathrm{Sr}_{0.3} \mathrm{MnO}_{3} / \mathrm{SrTiO}_{3}$ substrates by using pulsed laser deposition with Ag as top electrode. The intrinsic open-circuit voltage with no illumination was as large as $5.8 \mathrm{~V}$ in the device. They claimed that the polarization clearly played an essential role in the photovoltaic effects and the electro-migration of defects such as oxygen vacancies must be taken into account to understand electric-field-induced switching. They further claimed that the downward self-polarization would cause the positively charged oxygen vacancies to migrate toward the top surface to compensate for the negative polarization charge, as shown in Fig. 8. Later, in-depth study of the photovoltaic performance of these devices was done by Cao et al. [76]. With upward-polarized $\mathrm{Bi0}$.9La0.1FeO3 film, the open-circuit voltage measured at zero current was $-0.64 \mathrm{~V}$ in the dark and varies monotonically with light intensity. Upon exposure to $50 \mathrm{~mW}$ light, the open-circuit voltage changed to $+0.31 \mathrm{~V}$. Similarly, the short-circuit current measured at zero bias was $+3.1 \mathrm{nA}$ without illumination but switched to $-5.12 \mathrm{nA}$ under $50 \mathrm{~mW}$ irradiation. These results clearly indicated that the switchable photovoltaic effect originated from both the ferroelectric polarization of the $\mathrm{Bi} 0.9 \mathrm{La} 0.1 \mathrm{FeO} 3$ films, and the accumulation and distribution of 
the oxygen vacancies. In addition, the photovoltaic properties of Co-doping of $\mathrm{BiFeO}_{3}$ thin film was also researched. Multiferroic $\mathrm{BiFe}_{1-x} \mathrm{CoxO}_{3}(x=0,0.03,0.05,0.1)$ thin films were prepared on quartz substrates by using a sol-gel technique. The optical band gap of $\mathrm{BiFe}_{1-x} \mathrm{CoxO}_{3}$ films decreased from 2.66 to $2.53 \mathrm{eV}$ upon increasing the Co fraction from $x=0$ to 0.1 , as seen in Fig. 9 [77]. Similar results were obtained $\mathrm{Bi1}_{-x \mathrm{EurFO}}\left(\mathrm{BEFO}_{x}, x=0,0.03,0.05,0.07,0.1\right)$ thin films grown on $\mathrm{LaNiO}_{3}(\mathrm{LNO}) / \mathrm{Si}$ (100) substrates by pulsed-laser deposition, and the band gap of the thin film decreased with increasing fraction of Eu dopant, as shown in Fig. 10 [78]. K-substituted $\mathrm{BiFeO} 3$ films (BKFO) were fabricated on FTO/glass substrates by using the solution-gelation method [79]. The band gaps were 2.52, 2.59, 2.64, and $2.62 \mathrm{eV}$ for the Bi1-xKxFeO3 films with $x=0$, $0.05,0.10$, and 0.20 , respectively. The $\mathrm{Au} / \mathrm{Bi} 0.8 \mathrm{~K} 0.2 \mathrm{FeO} / \mathrm{FTO}$ device exhibited a maximum short-circuit current density of $1.32 \mu \mathrm{A} / \mathrm{cm}^{2}$ and maximum open-circuit voltage of $0.45 \mathrm{~V}$. Their work suggested that the reduction of the resistance while maintaining the ferroelectric is the key to the promotion of the photovoltaic effect. [Bi0.9 $\mathrm{La} 0.1]\left[\mathrm{Fe}_{0.97} \mathrm{Ti}_{0.02} \mathrm{Zr}_{0.01}\right] \mathrm{O}_{3}$ (BLFTZO) polycrystalline thin films were fabricated on $\mathrm{Pt} / \mathrm{TiO}_{2} / \mathrm{SiO}_{2} / \mathrm{Si}$ substrates by pulsed laser deposition [80]. The $V \mathrm{oc}$ and $J_{\mathrm{sc}}$ of $\mathrm{ZnO}: \mathrm{Al} / \mathrm{BLFTZO} / \mathrm{Pt}$ heterostructures device was $-0.022 \mathrm{~V}$ and -650 $\mu \mathrm{A} / \mathrm{cm}^{2}$, respectively, after positive poling, and changed significantly to $V_{\mathrm{oc}}-0.018 \mathrm{~V}$ and $\mathrm{Jsc}_{\mathrm{sc}}-$ $700 \mu \mathrm{A} / \mathrm{cm}^{2}$ after negative poling (see Fig. 11). The switchable photocurrent and photo-voltage response were attributed to the change of the polarization direction. Doubly ions substituted [Bi0.9La0.1][Fe0.97Ta0.03]03 (BLFTO) films were fabricated on $\mathrm{Pt} / \mathrm{TiO}_{2} / \mathrm{SiO}_{2} / \mathrm{Si}$ substrates by pulsed laser deposition, and the $V \mathrm{oc}$ and $J_{\mathrm{sc}}$ for the device was $0.20 \mathrm{~V}$ and $1.35 \mathrm{~mA} / \mathrm{cm}^{2}$, respectively (see Fig. 12) [81]. Agarwal et al. studied the switchable photovoltaic and photodiode characteristics of $\mathrm{Pt} /\left(\mathrm{Bi}_{0.9} \mathrm{Sm}_{0.1}\right)\left(\mathrm{Fe}_{0.97} \mathrm{Hf}_{0.03}\right) \mathrm{O}_{3} / \mathrm{LaNiO}_{3}(\mathrm{Pt} / \mathrm{BSFHO} / \mathrm{LNO})$ heterostructures integrated on $\mathrm{Si}(100)$ [82]. The maximum ... $\mathrm{sc}$ and $V \mathrm{oc}$ of the device are respectively 303 (- 
206) $\mu \mathrm{A} / \mathrm{cm}^{2}$ and $-0.32(0.26) \mathrm{V}$ after upward (downward) poling at $\pm 8 \mathrm{~V}$. Gupta et al. prepared semitransparent $\mathrm{Au} / \mathrm{BiFeO}_{3}$ derivative/ITO device by using chemical solution deposition technique [83]. A/B-site substitutional modification by rare earth $\mathrm{Ce}^{3+}$ and $\mathrm{Mn}^{2+}$ at respective $\mathrm{Bi} / \mathrm{Fe}$-site in host $\mathrm{BiFeO} 3$ led to the blue shift in optical band gap from 2.53 to 2.81 $\mathrm{eV}$ due to the decrease of the lattice parameters. While, the photovoltaic properties of the device upon doping were obviously enhanced because of the great increase of the remnant polarization. The most superior photovoltaic properties with $V_{\text {oc }}$ of $-0.25 \mathrm{~V}$ and ... $1_{\text {sc }}$ of -36 $\mu \mathrm{A} / \mathrm{cm}^{2}$ are obtained in the $\mathrm{Au} / \mathrm{Bi}_{0.88} \mathrm{Ce}_{0.12} \mathrm{Fe}_{0.9} \mathrm{Mn}_{0.1} \mathrm{O}_{3}$ (BCFMO)/ITO photovoltaic device.

\subsubsection{Photovoltaic effects in $\mathrm{BiFeO}_{3}$-based heterojunction thin films}

Nie et al. prepared $\mathrm{BiCrO}_{3} / \mathrm{BiFeO}_{3}(\mathrm{BCO} / \mathrm{BFO})$ bilayer composite films by using the solutiongelation technique [84]. It was shown that enhanced ferroelectric properties were observed in $\mathrm{BiCrO} 3 / \mathrm{BiFeO} 3$ bi-layer composite films resulting from the coupling between $\mathrm{BiFeO} 3$ and $\mathrm{BiCrO} 3$ layers and the measured leakage current density in $\mathrm{BiCrO}_{3} / \mathrm{BiFeO}_{3}$ bilayer composite films was $1.37 \times 10^{-4} \mathrm{~A} / \mathrm{cm}^{2}$ at an applied electric field of $67.81 \mathrm{kV} / \mathrm{cm}$, which is decreased by one to two orders of magnitude in comparison with the pure $\mathrm{BiFeO}_{3}$ and $\mathrm{BiCrO}_{3}$ films. The photovoltaic spectral responses of the normalized current for $\mathrm{BiCrO}_{3} / \mathrm{BiFeO}_{3}$ bilayer composite films presented a noteworthy red-shift towards visible region compared with pure $\mathrm{BiFeO}_{3}$ and $\mathrm{BiCrO}_{3}$ films. The 1 sc and $V$ oc of the $\mathrm{BiCrO}_{3} / \mathrm{BiFeO}_{3}$ bilayer composite films under white-light illumination were much higher than those of pure $\mathrm{BiFeO}_{3}$ and $\mathrm{BiCrO}_{3}$ films. Chakrabartty et al. studied photovoltaic properties of periodic multi-stacking of $\mathrm{BiFeO} / \mathrm{BiCrO}_{3}$ bilayers epitaxially deposited on $\mathrm{CaRuO}_{3}$-coated $\mathrm{LaAlO}_{3}$ substrates by pulsed laser deposition [85]. Among of all devices, 120 -nm-thick $\mathrm{BiFeO}_{3}-\mathrm{BiCrO}_{3}$ multilayer-based 
device exhibited highest photovoltage of $1.2 \mathrm{eV}$, and 60 -nm-thick $\mathrm{BiFeO}_{3}-\mathrm{BiCrO}_{3}$ ultilayerbased device had the highest short-current of $-0.013 \mathrm{~mA} / \mathrm{cm}^{2}$. Gupta et al, prepared $\mathrm{BiFeO}_{3} / \mathrm{BaTiO}_{3} / \mathrm{BiFeO}_{3} / \mathrm{BaTiO}_{3}$ multilayered thin film on $\mathrm{Pt} / \mathrm{Ti} / \mathrm{SiO}_{2} / \mathrm{Si}$ substrates by using chemical solution deposition, as seen in Fig. 13, which showed a ..1 sc value of $-12.65 \mu \mathrm{A} / \mathrm{cm}^{2}$ and a $V_{o c}$ value of $-1.43 \mathrm{~V}$, obviously higher than those reported by other workers for photovoltaic device with single layer of ferroelectric materials [86]. The enhanced photovoltaic response was attributed to the high internal depolarization field caused by the large remnant polarization more effectively separating photo-generated charge carriers. A new approach of utilizing $\mathrm{BiFeO}_{3}$ as a light-absorbing sensitizer was developed to interface with charge-transporting $\mathrm{TiO}_{2}$ nanoparticles by Wu et al, as shown in Fig. 14 [87]. This mesoporous all-oxide architecture, similar to that of dye-sensitized solar cells, could effectively facilitate the extraction of photocarriers. Under the standard AM1.5 $\left(100 \mathrm{~mW} \mathrm{~cm}{ }^{-2}\right)$ irradiation, the optimized cell showed an $V$ oc of $0.67 \mathrm{~V}$, which could be enhanced to $1.0 \mathrm{~V}$ by tailoring the bias history. Besides, a fill factor of 55\% was also achieved, which was much higher than those reported in previous. Fan et al. studied the photovoltaic effect in a metal/semiconductor/ ferroelectric/ metal hetero-structure of $\mathrm{In}_{2} \mathrm{O}_{3}-\mathrm{SnO}_{2} / \mathrm{ZnO} / \mathrm{BiFeO}_{3} / \mathrm{Pt}(\mathrm{ITO} / \mathrm{ZnO} / \mathrm{BFO} / \mathrm{Pt})$ multilayer thin films [10]. The device with the hetero-layered structure exhibited a ... sc of as high as $340 \mu \mathrm{A} / \mathrm{cm}^{2}$ and an energy conversion efficiency of up to $0.33 \%$ under blue monochromatic illumination. The significant increase of the photocurrent in ITO/ZnO/BFO/ Pt devices compared with that of ITO/BFO/Pt devices was due to the abundant e-h pairs generated by $\mathrm{ZnO}$. A Schottky barrier and $\mathrm{nn}^{+}$-n junction were formed at the $\mathrm{BiFeO}_{3} / \mathrm{Pt}$ and $\mathrm{ZnO} / \mathrm{BiFeO}_{3}$ interfaces, respectively. Therefore, two built-in electric fields appear at the two interfaces and were constructively responsible for the separation and transport of photoexcited 
e-h pairs. Huang et al. fabricated $\mathrm{p}-\mathrm{i}-\mathrm{n}$ het-erojunction devices based on double perovskite multiferroic $\mathrm{Bi}_{2} \mathrm{FeCrO}_{6}$ thin films [88]. Under 1 sun illumination, the optimized $\mathrm{p}-\mathrm{i}-\mathrm{n}$ device yielded an $V_{\mathrm{oc}}$ of $0.53 \mathrm{~V}$ and a. $.1 \mathrm{sc}$ of $8.0 \mathrm{~mA} \mathrm{~cm} \mathrm{c}^{-2}$, leading to a PCE of $2.0 \%$. The enhancement of the photovoltaic properties was because of the function of the two depletion regions in $\mathrm{p}-\mathrm{i}-\mathrm{n}$ hetero-structures (operative at the $\mathrm{p}-\mathrm{i}$ and $\mathrm{i}-\mathrm{n}$ interfaces). In very recently, Nechache prepared $\mathrm{Bi}_{2} \mathrm{FeCrO}_{6}$ thin film achieving simultaneously a narrow band gap of 1.4 $\mathrm{eV}$ and large remnant polarization by tailoring the $\mathrm{Fe} / \mathrm{Cr}$ cation ordering and the ordered domain size, and obtained a PCE as high as $8.1 \%$, which was the largest value reported in ferroelectric photovoltaic devices, in a multilayer configuration (see Fig. 15) [891. The superior photovoltaic properties are because their broad absorption peaks covering a large fraction of the solar spectrum between the visible and ultraviolet regions, leading to a much more efficient absorption of incident radiation than each individual layer and thus obviously increased $J_{\mathrm{sc}}\left(20.6 \mathrm{~mA} / \mathrm{cm}^{2}\right)$.

\subsection{Photovoltaic effects in BiFeO3-based nanomaterials}

$\mathrm{BiFeO}_{3}$-based nanomaterials mainly include nanotubes, nanofibers, nanowires, and nanoparticles. The grain sizes in $\mathrm{BiFeO}_{3}$-based nano-materials are generally believed to be smaller than that in ceramics and films. Sudakar et al. demonstrated a tunable band gap from $2.32 \mathrm{eV}$ to $2.09 \mathrm{eV}$ in phase-pure $\mathrm{BiFeO}_{3}$ nanoparticles by controlling the particle size from 65 $\mathrm{nm}$ to $5 \mathrm{~nm}[901$. The reduction in the band gap with decreasing particle size was attributed to the competing effects of mi-crostrain, oxygen defects, and Coulombic interactions. Multiferroic $\mathrm{Bi}_{1-x} \mathrm{Eu}_{x} \mathrm{Fe}_{0.975} \mathrm{Mn}_{0.025} \mathrm{O}_{3}(x=0.025,0.05,0.075,0.1$; called BEFM1, BEFM2, BEFM3, and BEFM4, respectively) nanoparticles were prepared by the solution-gelation route $[911$. Co- 
substitution by Eu and Mn could trigger a cubic phase transformation. The particle size in the samples decreased from 200 to $500 \mathrm{~nm}$ to $-100 \mathrm{~nm}$ after doping. UV-vis absorption spectra demonstrated a gradually decrease in the direct optical band gap from 2.40 to $-1.49 \mathrm{eV}$ upon doping $\mathrm{BiFeO}_{3}$ with $\mathrm{Eu}$ and $\mathrm{Mn}$, implying electronic transitions between $\mathrm{O} 2 p$ states and $\mathrm{Fe}$ $3 d$ states. Han et al. prepared $\mathrm{Na}$ and $\mathrm{Ru}$ co-doped $\mathrm{BiFeO}_{3}$ nanoparticles by using a solutiongelation method and investigated their optical properties [92]. In their work, the change in Fe$\mathrm{O}$ bond length and Fe-O-Fe bond angle upon Ru substitution finally led to the shrinking of the optical band gap. $\mathrm{BiFeO}_{3}$ nanowires were directly deposited on an electrode patterned substrate by using a solution-gelation-based electrospinning technique [93]. The measured carrier lifetimes in $\mathrm{BiFeO}_{3}$ nanowire were three orders of magnitude greater than the values reported for the $\mathrm{BiFeO}_{3}$ bulk. Fei et al. synthesized $\mathrm{BiFeO}_{3}$ nanofibers via a sol-gel-based electrospinning process followed by thermal treatment [94]. The $\mathrm{BiFeO}_{3}$ nanofibers exhibited excellent ferroelectric photovoltaic properties, with a photocurrent density of $1 \mathrm{~mA} / \mathrm{cm}^{2}$, which was about 10 times larger than the literature data for $\mathrm{BiFeO}_{3}$ thin films (see Fig. 16). The reasons for the enhanced photovoltaic properties may be related to several factors: (1) the nanofibers were free-standing, allowing the ferroelectric domains to switch more freely and efficiently; (2) the na-nofibers could trap more photons due to the geometric confinement. Recently, Khan et al. have studied the photovoltaic effect of pure and $\mathrm{Pr} / \mathrm{Cr}$-doped polycrystalline $\mathrm{BiFeO}_{3}$ nanotubes fabricated via the wet chemical template-assisted route [95]. The PCE (-0.207\%) of pure $\mathrm{BiFeO}_{3}$ nanotubes was found to be enhanced by several orders of magnitude in comparison with that reported in bulk $\mathrm{BiFeO}_{3}$ due to the special nanoscale geometry of the nanotubes, which could induce substantially large photocurrents. Pr-doped nanotubes provide highest values of PCE $(-0.5 \%)$. The change in the values of the PCE upon 
metal doping can be explained based on the change in the concentration and mobility of the photogenerated non-equilibrium carriers in the nano-tubes due to the incorporation of the dopant ions.

\section{Summary and prospects}

Table 1 summarizes the performance of various $\mathrm{BiFeO}_{3}$ materials, including ceramics, thin films, and nanomaterials for photovoltaic devices application. As seen, in the past few years, huge progress has been achieved in $\mathrm{BiFeO}_{3}$-based ferroelectric photovoltaic devices. For instance, a large $V_{\text {oc }}$ of $1.43 \mathrm{~V}$ was obtained in the $\mathrm{Au} / \mathrm{BiFeO}_{3} / \mathrm{BaTiO}_{3} / \mathrm{Pt}$ device and the PCE of the $\mathrm{ITO} / \mathrm{Bi}_{2} \mathrm{FeCrO}_{6} / \mathrm{Nb}: \mathrm{SrTiO}_{3}$ multilayer devices could be as high as $8.1 \%$, which is comparable with those of some semiconductor photovoltaic devices $[3,86,89]$. However, the PCE of many $\mathrm{BiFeO}_{3}$-based ferroelectric photovoltaic devices is still too low for practical applications. This is mainly attributed to the following two reasons: (1) although the band gap of $\mathrm{BiFeO}_{3}$ is lower than those of conventional ferroelectric materials, it still exceeds the ideal value of $\sim 1.4 \mathrm{eV}$ (corresponding to the highest theoretical power conversion efficiency for single-junction photovoltaic devices), resulting in an overall poor sunlight absorption capability;

(2) $\mathrm{BiFeO}_{3}$ is an insulating material with very low electrical conductivity, thus leading to a quite small output photocurrent. Based on above discussion, it is clear that in order to improve further the PCE of BiFeO3-based ferroelectric photovoltaic devices, it is the key to increasing the .. $1_{\mathrm{sc}}$. Thus, in the future work, we should pay more attention to the increase of the ...1sc in $\mathrm{BiFeO}_{3}$ devices and focus the following aspects: (1) preparing highly crystalline $\mathrm{BiFeO}_{3}$ thin films with minimum defects to improve carrier transportation capacity; (2) adjusting preparation or doping technology to decrease the band gap of $\mathrm{BiFeO}_{3}$-based materials and thus allowing absorption of 
more light in visible and ultraviolet regions; (3) developing $\mathrm{BiFeO}_{3}$-based ferroelectric photovoltaic devices composed of multi-layers with various band gaps so that their absorption peaks can cover a large fraction of the solar spectrum between the visible and ultraviolet regions; (4) a cascade of $\mathrm{BiFeO}_{3}$ with other materials, such as $\mathrm{BiVO}_{4}, \mathrm{Cu}_{2} \mathrm{O}, \mathrm{ZnO}$, etc. to effectively separate and collect photoexcited e-h pairs. Overall, it is expected that this review will provide some guidance in the development of $\mathrm{BiFeO}_{3}$-based ferroelectric photovoltaic devices with large open-circuit voltage, high short-circuit, superior power conversion efficiency, good stability and long cycle life.

\section{Acknowledgements}

This work was supportedby the National Natural Science Foundation of China (Grant Nos. 61274010, 51572073, 51602093, 11774082, 51872079), the Natural Science Foundation of Hubei Province (Grant Nos. 2015CFA038, 2016AAA031, 2018CFB700), State Key Laboratory of Advanced Technology for Materials Synthesis and Processing (Wuhan University of Technology; Grant No. 2018-KF-16). 


\section{References}

[1] J.P. Correabaena, M. Saliba, T. Buonassisi, M. Grätzel, A. Abate, W. Tress, A. Hagfeldt, Promises and challenges of perovskite solar cells, Science 358 (2017) 739-744.

[2] M.M. Yang, D.J. Kim, M. Alexe, Flexo-photovoltaic effect, Science 360 (2018) 904907.

[3] M.A. Green, Y. Hishikawa, E.D. Dunlop, D.H. Levi, J. Hohl-Ebinger, A.W.Y. HoBaillie, Solar cell efficiency tables (version 52), Prog. Photovolt: Res. Appl. 26 (2018) 427-436.

[4] P. Lopez-Varo, L. Bertoluzzi, J. Bisquert, M. Alexe, M. Coll, J. Huang, J.A. JimenezTejada, T. Kirchartz, R. Nechache, F. Rosei, Y. Yuan, Physical aspects of ferro-electric semiconductors for photovoltaic solar energy conversion, Phys. Rep. 653 (2016) 1-40.

[5] B. Chen, X. Zheng, Y. Bai, N.P. Padture, J. Huang, Progress in tandem solar cells based on hybrid organic-inorganic perovskites, Adv. Energy. Mater. 7 (2017) 1602400.

[6] M.I.H. Ansari, A. Qurashi, M.K. Nazeeruddin, Frontiers, opportunities, and challenges in perovskite solar cells: a critical review, J. Photoch. Photobio. C 35 (2018) 1-24.

[7] M.D. Bhatt, J.S. Lee, Current progress and scientific challenges in the advancement of organic-inorganic lead halide perovskite solar cells, New. J. Chem. 41 (2017) 1050810527.

[8] J. Hou, O. Inganäs, R.H. Friend, F. Gao, Organic solar cells based on non-fullerene acceptors, Nat. Mater. 17 (2018) 119-128.

[9] Z. Yang, A. Rajagopal, A.K. Jen, Ideal bandgap organic-inorganic hybrid perovskite solar cells, Adv. Mater. 29 (2017) 1704418.

${ }_{[10]}$ Z. Fan, K. Yao, J. Wang, Photovoltaic effect in an indium-tin-oxide/ZnO/BiFeO3/ $\mathrm{Pt}$ heterostructure, Appl. Phys. Lett. 105 (2014) 162903.

[11] Y. Chen, J.W. Chen, S.B. Yang, Y. Li, X.L. Gao, M. Zeng, Z. Fan, X.S. Gao, X.B. Lu, J.M. Liu, A bi-functional ferroelectric $\mathrm{Pb}(\mathrm{Zr} 0.52 \mathrm{Ti} 0.48) \mathrm{O} 3$ films: energy storage properties and ferroelectric photovoltaic eff ;ects, Mater. Res. Bull. 107 (2018) 456-461.

[12] J. Oh, H.C. Yuan, H.M. Branz, An 18.2\%-efficient black-silicon solar cell achieved through control of carrier recombination in nanostructures, Nat. Nanotechnol. 7 (2012) 743-748.

[13] G. Chanussot, Physical models for the photoferroelectric phenomena, Ferroelectrics 20 (1978) 37-50.

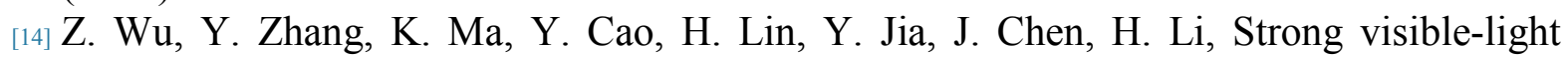
photovoltaic effect in multiferroic $\mathrm{Pb}(\mathrm{Fe} 1 / 2 \mathrm{~V} 1 / 2) \mathrm{O} 3$ bulk ceramics, Phys. Status. Solidi. R 8 (2014) 36-39.

[15] B. O’Regan, M. Grätzel, A low-cost, high-efficiency solar cell based on dye-sensitized colloidal TiO2 films, Nature 353 (1991) 737-740.

[16] J.J. Loferski, Theoretical considerations governing the choice of the optimum semiconductor for photovoltaic solar energy conversion, J. Appl. Phys. 27 (1956) 777-784.

[17] A. Goetzberger, C. Hebling, H.W. Schock, Photovoltaic materials, history, status and outlook, Mater. Sci. Eng. R 40 (2003) 1-46.

[18] L.Z. Tan, F. Zheng, S.M. Young, F. Wang, S. Liu, A.M. Rappe, Shift current bulk photovoltaic effect in polar materials-hybrid and oxide perovskites and beyond, Npj. Comput. Mater. 2 (2016) 16026. 
[19] Y. Ren, F. Nan, L. You, Y. Zhou, Y. Wang, J. Wang, X. Su, M. Shen, L. Fang, Enhanced photoelectrochemical performance in reduced graphene oxide/ $\mathrm{BiFeO} 3$ heterostructures, Small 13 (2017) 160345.

[20] C. Paillard, X. Bai, I.C. Infante, M. Guennou, G. Geneste, M. Alexe, J. Kreisel, B. Dkhil, Photovoltaics with ferroelectrics: current status and beyond, Adv. Mater. 28 (2016) 51535168.

[21] X. Yang, X. Su, M. Shen, F. Zheng, Y. Xin, L. Zhang, M. Hua, Y. Chen, V.G. Harris, Enhancement of photocurrent in ferroelectric films via the incorporation of narrow bandgap nanoparticles, Adv. Mater. 24 (2012) 1202-1208.

[22] H. Huang, Solar energy: ferroelectric photovoltaics, Nat. Photonics 4 (2010) 134-135.

[23] Q.F. Zhang, F. Xu, M.J. Xu, L. Li, Y.M. Lu, M.K. Li, P. Li, M. Li, G. Chang, Y.B. He, Lead-free perovskite ferroelectric thin films with narrow direct band gap suitable for solar cell applications, Mater. Res. Bull. 95 (2017) 56-60.

[24] M.A. Jalaja, S. Dutta, Switchable photovoltaic properties of multiferroic KBiFe2O5, Mater. Res. Bull. 88 (2017) 9-13.

[25] A. Bhatnagar, C.A. Roy, K.Y. Heon, D. Hesse, M. Alexe, Role of domain walls in the abnormal photovoltaic effect in BiFeO3, Nat. Commun. 4 (2013) 2835.

[26] Y. Yuan, Z. Xiao, B. Yang, J. Huang, Arising applications of ferroelectric materials in photovoltaic devices, J. Mater. Chem. A 2 (2014) 6027-6041.

[27] Y. Liu, S. Wang, Z. Chen, L. Xiao, Applications of ferroelectrics in photovoltaic devices, Sci. China. Mater. 59 (2016) 851-866.

[28] R. Gao, C. Fu, W. Cai, G. Chen, X. Deng, X. Cao, Thickness dependence of photovoltaic effect in $\mathrm{BiFeO} 3$ thin films based on asymmetric structures, J. Electron. Mater. 46 (2017) 2373-2378.

[29] W.H. Jiang, W. Cai, Z.B. Lin, C.L. Fu, Effects of Nd-doping on optical and photovoltaic properties of barium titanate thin films prepared by sol-gel method, Mater. Res. Bull. 48 (2013) 3092-3097.

[30] L. Pintilie, C. Dragoi, I. Pintilie, Interface controlled photovoltaic effect in epitaxial $\mathrm{Pb}(\mathrm{Zr}, \mathrm{Ti}) \mathrm{O} 3$ films with tetragonal structure, J. Appl. Phys. 110 (2011) 044105.

[31] J. Chen, C. Nie, Y. Bai, S. Zhao, The photovoltaic spectral response regulated by band gap in Zr doped Bi4Ti3O12 thin films, J. Mater. Sci-Mater. El. 26 (2015) 5917-5922.

[32] S. Das, S. Ghara, P. Mahadevan, S. Athinarayanan, J. Gopalakrishnan, D.D. Sarma, Designing a lower bandgap bulk ferroelectric material with a sizable polarization at the room temperature, ACS Energy Lett. 3 (2018) 1176-1182.

[33] R.E. Cohen, Origin of ferroelectricity in perovskite oxides, Nature 358 (1992) 136-138.

[34] N.A. Benedek, C.J. Fennie, Why Are There So Few Perovskite Ferroelectrics?, J. Phys. Chem. C. 117 (2015) 13339-13349.

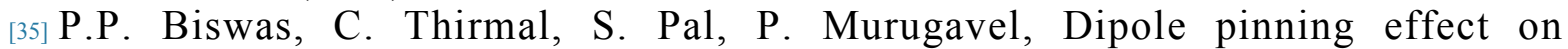
photovoltaic characteristics of ferroelectric $\mathrm{BiFeO}_{3}$ films, J. Appl. Phys. 123 (2018) 024101.

[36] M. Bibes, A. Barthelemy, Multiferroics: towards a magnetoelectric memory, Nat. Mater. 7 (2008) 425-426.

[37] J.G. Wu, Z. Fan , D.Q. Xiao, J.G. Zhu, J. Wang, Multiferroic bismuth ferrite- based materials for multifunctional applications: Ceramic bulks, thin films and nanostructures, Prog. Mater. Sci. 84 (2016) 335-402. 
[38] J. Silva, A. Reyes, H. Esparza, H. Camacho, L. Fuentes, BiFeO3: A Review on Synthesis, Doping and Crystal Structure, Integr. Ferroelect. 126 (2011) 47-59.

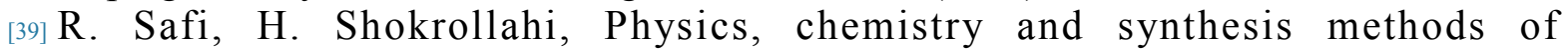
nanostructured bismuth ferrite $\left(\mathrm{BiFeO}_{3}\right)$ as a ferroelectro-magnetic material, Prog. Solid. State. Ch. 40 (2012) 6-15.

[40] K.Y. Yun, R. Dan, T. Kanashima, M. Okuyama, Enhancement of electrical properties in polycrystalline $\mathrm{BiFeO}_{3}$ thin films, Appl. Phys. Lett. 89 (2006)192902.

[41] M. Alexe, D. Hesse, Tip-enhanced photovoltaic effects in bismuth ferrite, Nat. Commun. 2 (2011) 256.

[42] W. Ji, K. Yao, Y.C. Liang, Bulk photovoltaic effect at visible wavelength in epitaxial ferroelectric $\mathrm{BiFeO}_{3}$ thin films, Adv. Mater. 22 (2010) 1763-1766.

[43] S.Y. Yang, L.W. Martin, S.J. Byrnes, T.E. Conry, S.R. Basu, D. Paran, L. Reichertz, J. Ihlefeld, C. Adamo, A. Melville, Y.H. Chu, C.H. Yang, J.L. Musfeldt, D.G. Schlom, J.W. Ager, R. Ramesh, Photovoltaic effects in $\mathrm{BiFeO}_{3}$, Appl. Phys. Lett. 95 (2009) 062909.

[44] W. Dong, Y. Guo, B. Guo, H. Liu, H. Li, H. Liu, Enhanced photovoltaic properties in polycrystalline $\mathrm{BiFeO}_{3}$ thin films with rhombohedral perovskite structure deposited on fluorine doped tin oxide substrates, Mater. Lett. 88 (2012) 140-142.

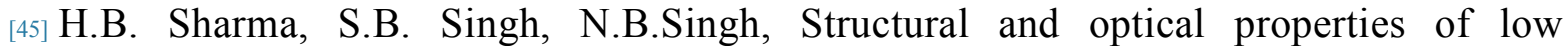
temperature synthesized Nanostructured $\mathrm{BiFeO}_{3}$ thin films, Physica. B. 406 (2011) 351-353.

[46] T. Choi, S. Lee, Y.J. Choi, V. Kiryukhin, S.W. Cheong, Switchable ferroelectric diode and photovoltaic effect in $\mathrm{BiFeO}_{3}$, Science. 324 (2009) 63-66.

[47] X. Li, S. Zhao, Q. Lu, Z. Wang, Ferroelectric photovoltaic response near to visible light region in $\mathrm{BiFeO}_{3} / \mathrm{BiVO}_{4}$ composite films, Int. J. Hydrogen. Energ. 42 (2017) 1824618251.

[48] S.Y. Yang, J. Seidel, S.J. Byrnes, P. Shafer, C.H. Yang, M.D. Rossell, P. Yu, Y.H. Chu, J.F. Scott, J.W. Ager III, L.W. Martin, R. Ramesh, Above-bandgap voltages from ferroelectric photovoltaic devices, Nat. Nanotechnol. 5 (2010) 143-147.

[49] R.L. Gao, W. Cai, G. Chen, X.L. Deng, X.L. Cao, C.L. Fu, Enhanced ferroelectric photovoltaic effect based on converging depolarization field, Mater. Res. Bull. 84 (2016) 93-98.

[50] C.S. Tu, C.M. Hung, V.H. Schmidt, R.R. Chien, M.D. Jiang, J. Anthoninappen, The origin of photovoltaic responses in $\mathrm{BiFeO} 3$ multiferroic ceramics, J. Phys: Condens. Mater. 24 (2012) 495902.

[51] C.M. Hung, M.D. Jiang, J. Anthoninappen, C.S. Tu, Photo-induced electric phenomena in antiferromagnetic BiFeO3 ceramics, J. Appl. Phys. 113 (2013) 17D905.

[52] A.N. Kalinkin, V.M. Skorikov, BiFeO3films and single crystals as a promising inorganic material for spintronics, Russ. J. Inorg. Chem. 55 (2010) 1794-1809.

[53] M.K. Singh, S. Ryu, H.M. Jang, Polarized Raman scattering of multiferroic BiFeO3 thin films with pseudo-tetragonal symmetry, Phys. Rev. B 72 (2005) 132101.

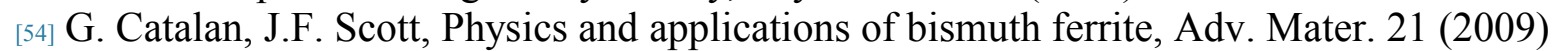
2463-2485.

[55] J. Wang, J.B. Neaton, H. Zheng, V. Nagarajan, S.B. Ogale, B. Liu, D. Viehland, V. Vaithyanathan, D.G. Schlom, U.V. Waghmare, N.A. Spaldin, K.M. Rabe, M. Wuttig, R. Ramesh, Epitaxial BiFeO3 multiferroic thin film heterostructures, Science 299 (2003) 1719-1722. 
${ }_{[56]}$ K.Y. Yun, M. Noda, M. Okuyama, H. Saeki, H. Tabata, K. Saito, Structural and multiferroic properties of $\mathrm{BiFeO} 3$ thin films at room temperature, J. Appl. Phys. 96 (2004) 3399-3403.

[57] J. Wang, Zheng H, Z. Ma, S. Prasertchoung, M. Wuttig, R. Droopad, J. Yu, K. Eisenbeiser, R. Ramesh, Epitaxial BiFeO3 thin films on Si, Appl. Phys. Lett. 85 (2004) 2574-2576.

${ }_{[58]}$ G. Xu, K. Hiraka, G. Shirane, J. Li, J. Wang, D. Viehland, Low symmetry phase in (001) BiFeO3 epitaxial constrained thin films, Appl. Phys. Lett. 86 (2005) 182905.

[59] A. Kumar, R.C. Rai, N.J. Podraza, S. Denev, M. Ramirez, Y.H. Chu, L.W. Martin, J. Ihlefeld, T. Heeg, J. Schubert, D.G. Schlom, J. Orenstein, R. Ramesh, R.W. Collins, J.L. Musfeldt, V. Gopalan, Linear and nonlinear optical properties of BiFeO3, Appl. Phys. Lett. 92 (2008) 121915.

[60] H. Wang, Y. Zheng, M.Q. Cai, H. Huang, H.L.W. Chan, First-principles study on the electronic and optical properties of BiFeO3, Solid. State. Commun. 149 (2009) 641-644.

[61] C.M. Hung, C.S. Tu, W.D. Yen, L.S. Jou, M.D. Jiang, V.H. Schmidt, Photovoltaic phenomena in BiFeO3 multiferroic ceramics, J. Appl. Phys. 111 (2012) 07D912.

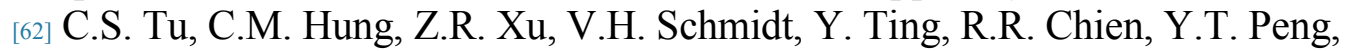
J. Anthoninappen, Calcium-doping effects on photovoltaic response and structure in multiferroic BiFeO3 ceramics, J. Appl. Phys. 114 (2013) 124105.

[63] C.M. Hung, C.S. Tu, Z.R. Xu, L.Y. Chang, V.H. Schmidt, R.R. Chien, W.C. Chang, Effect of diamagnetic barium substitution on magnetic and photovoltaic properties in multiferroic BiFeO3, J. Appl. Phys. 115 (2014) 17D901.

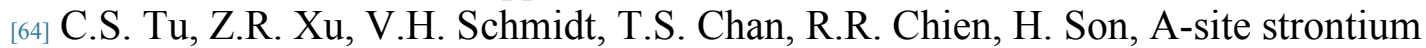
doping effects on structure, magnetic, and photovoltaic properties of (Bi1- $x \mathrm{Sr} x$ ) FeO3- $\delta$ multiferroic ceramics, Ceram. Int. 41 (2015) 8417-8424.

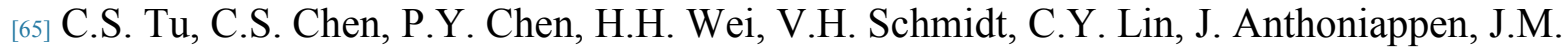
Lee, Enhanced photovoltaic effects in A-site samarium doped $\mathrm{BiFeO} 3$ ceramics: the roles of domain structure and electronic state, J. Eur. Ceram. Soc. 36 (2016) 1149-1157.

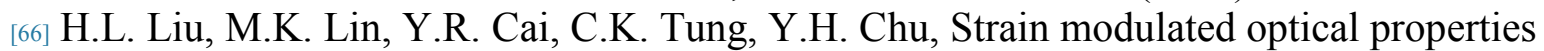
in BiFeO3 thin films, Appl. Phys. Lett. 103 (2013) 181907.

${ }_{[67]}$ H.W. Chang, F.T. Yuan, Y.C. Yu, P.C. Chen, C.R. Wang, C.S. Tu, S.U. Jen, Photovoltaic property of sputtered BiFeO3 thin films, J. Alloy. Compd. 574 (2013) 402-406.

[68] P.P. Biswas, T. Chinthakuntla, D. Duraisamy, G. Nambi Venkatesan, S. Venkatachalam, P. Murugavel, Photovoltaic and photo-capacitance effects in ferroelectric BiFeO3 thin film, Appl. Phys. Lett. 110 (2017) 192906.

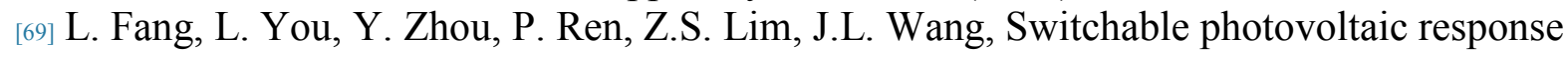
from polarization modulated interfaces in BiFeO3 thin films, Appl. Phys. Lett. 104 (2014) 142903.

[70] Z. Peng, Y. Wang, B. Liu, Evidence of interface dominated photovoltaic effect of Ptsandwiched polycrystalline BiFeO3 thin film capacitors, Mat. Sci. Semicon. Proc. 35 (2015) 115-119.

[71] M.M. Yang, Z.D. Luo, D.J. Kim, M. Alexe, Bulk photovoltaic effect in monodomain BiFeO3 thin films, Appl. Phys. Lett. 110 (2017) 183902.

[72] B. Kundys, M. Viret, D. Colson, D.O. Kundys, Light-induced size changes in $\mathrm{BiFeO} 3$ crystals, Nat. Mater. 9 (2010) 803-805. 
3] S. Kooriyattil, R.K. Katiyar, S.P. Pavunny, G. Morell, R.S. Katiyar, Photovoltaic properties of Aurivillius phase Bi5FeTi3O15 thin films grown by pulsed laser deposition, Appl. Phys. Lett. 105 (2014) 072908.

[74] R.L. Gao, H.W. Yang, Y.S. Chen, J.R. Sun, Y.G. Zhao, B.G. Shen, The study of open circuit voltage in $\mathrm{Ag} / \mathrm{Bi0} .9 \mathrm{La} 0.1 \mathrm{FeO} 3 / \mathrm{La} 0.7 \mathrm{Sr} 0.3 \mathrm{MnO} 3$ heterojunction structure, Physica. $\mathrm{B}$. 432 (2014) 111-115.

${ }^{[75]}$ R.L. Gao, H.W. Yang, Y.S. Chen, J.R. Sun, Y.G. Zhao, B.G. Shen, Oxygen vacancies induced switchable and nonswitchable photovoltaic effects in $\mathrm{Ag} / \mathrm{Bi} 0.9 \mathrm{La} 0.1 \mathrm{FeO} 3 / \mathrm{La} 0.7 \mathrm{Sr} 0.3 \mathrm{MnO} 3$ sandwiched capacitors, Appl. Phys. Lett. 104(2014) 031906.

[76] R.Gao, C. Fu, W. Cai, G. Chen, X. Deng, X. Cao, Switchable photovoltaic effect in $\mathrm{Au} / \mathrm{Bi} 0.9 \mathrm{La} 0.1 \mathrm{FeO} 3 / \mathrm{La} 0.7 \mathrm{Sr} 0.3 \mathrm{MnO} 3$ heterostructures, Mater. Chem. Phys. 181(2016) 277283.

[77] L. Peng, H. Deng, J. Tian, Q. Ren, C. Peng, Z. Huang, P. Yang, J. Chu, Influence of Co doping on structural, optical and magnetic properties of $\mathrm{BiFeO}_{3}$ films deposited on quartz substrates by sol-gel method, Appl. Surf. Sci. 268 (2013) 146-150.

[78] J. Liu, H. Deng, H.Cao, X. Zhai, J. Tao, L. Sun, P. Yang, J. Chu, Influence of rare-earth elements doping on structure and optical properties of $\mathrm{BiFeO}_{3}$ thin films fabricated by pulsed laser deposition, Appl. Surf. Sci. 307 (2014) 543-547.

[79] Y. Li, X. Liu, Y. Sun, S. Sheng, H. Liu, P. Yang, S. Yang, Enhanced photovoltaic effect in K substitutedBiFeO3 films, J. Alloy. Compd. 644 (2015) 602-606.

${ }_{[80]}$ R.K. Katiyar, Y. Sharma, P. Misra, V.S. Puli, S. Sahoo, A. Kumar, J.F. Scott, G. Morell, B.R. Weiner, R.S. Katiyar, Studies of the switchable photovoltaic effect in co-substituted $\mathrm{BiFeO}_{3}$ thin films, Appl. Phys. Lett. 105 (2014) 172904.

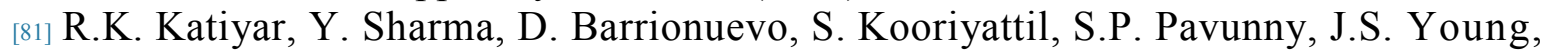
G. Morell, B.R. Weiner, R.S. Katiyar, J.F. Scott, Ferroelectric photovoltaic properties in doubly substituted (Bi0.9La0.1)(Fe0.97Ta0.03)O3 thin films, Appl. Phys. Lett. 106 (2015) 082903.

${ }_{[82]}$ R. Agarwal, Y. Sharma, R.S. Katiyar, Switchable photovoltaic and polarization modulated rectification in Si-integrated $\mathrm{Pt} /(\mathrm{Bi} 0.9 \mathrm{Sm} 0.1)(\mathrm{Fe} 0.97 \mathrm{Hf} 0.03) \mathrm{O}_{3} / \mathrm{LaNiO}_{3}$ heterostructures, Appl. Phys. Lett. 107 (2015) 162904.

[83] S. Gupta, M. Tomar, V. Gupta, Ferroelectric photovoltaic response to structural transformations in doped $\mathrm{BiFeO} 3$ derivative thin films, Mater. Design.105 (2016) 296-300.

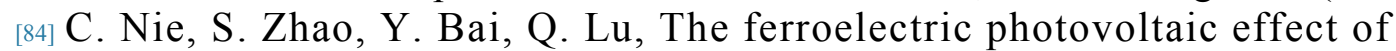
$\mathrm{BiCrO}_{3} / \mathrm{BiFeO}_{3}$ bilayer composite films, Ceram. Int. 42 (2016) 14036-14040.

[85] J. Chakrabartty, R. Nechache, S. Li, M. Nicklaus, A. Ruediger, F. Rosei, Photovoltaic Properties of Multiferroic $\mathrm{BiFeO}_{3} / \mathrm{BiCrO}_{3}$ Heterostructures, J. Am. Ceram. Soc. 97 (2014) 1837-1840.

[86] S. Sharma, M. Tomar, A. Kumar, N.K. Puri, V. Gupta, Photovoltaic effect in $\mathrm{BiFeO}_{3} / \mathrm{BaTiO}_{3}$ multilayer structure fabricated by chemical solution deposition technique, J. Phys. Chem. Solids. 93 (2016) 63-67.

${ }_{[87]}$ L. Wang, H. Ma, L. Chang, C. Ma, G. Yuan, J. Wang, T. Wu, Ferroelectric BiFeO3 as an Oxide Dye in Highly Tunable Mesoporous All-Oxide Photovoltaic Heterojunctions, Small. 13 (2017) 1602355. 
${ }^{[88]}$ W. Huang, C. Harnagea, D. Benetti, M. Chaker, F. Rosei, R. Nechache, Multiferroic $\mathrm{Bi}_{2} \mathrm{FeCrO} 6$ based p-i-n heterojunction photovoltaic devices, J. Mater. Chem. A. 5 (2017) 10355-10364.

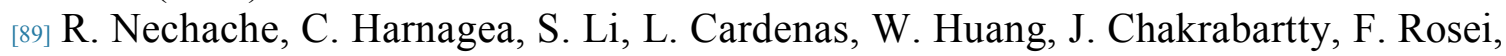
Bandgap tuning of multiferroic oxide solar cells, Nat. Photonics. 9 (2014) 61-67.

${ }_{[90]}$ P.S.V. Mocherla, C.Karthik, R. Ubic, M.S.R. Rao, C. Sudakar, Tunable bandgap in $\mathrm{BiFeO}_{3}$ nanoparticles: The role of microstrain and oxygen defects, Appl. Phys. Lett. 103 (2013) 022910.

[91] Y. Zhu, C. Quan, Y. Ma, Q. Wang, W. Mao, X. Wang, J. Zhang, Y. Min, J. Yang, X. Li, W. Huang, Effect of Eu, Mn co-doping on structural, optical and magnetic properties of $\mathrm{BiFeO}_{3}$ nanoparticles, Mat. Sci. Semicon. Proc. 57 (2017) 178-184.

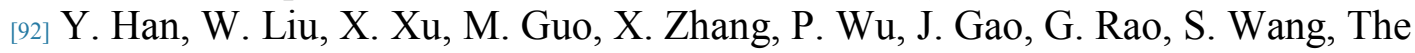
Abnormal Optical Property and Room-Temperature Exchange Bias Behavior in Na- and Ru-Codoped BiFeO3 Nanoparticles, J. Am. Ceram. Soc. 99 (2016) 3616-3622. 


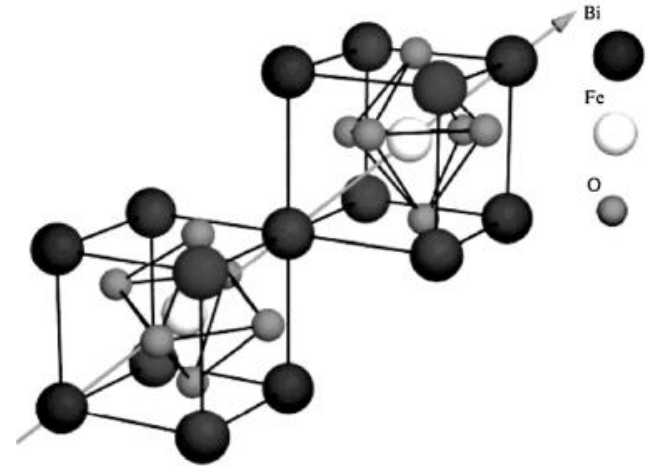

(a)

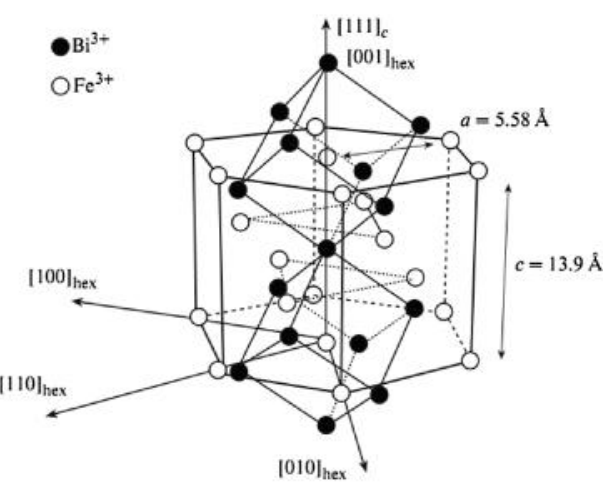

(b)

Fig. 2. Crystal structures of BiFeO3: (a) rhombohedral structure, and (b) hexagonal structure [52]. Copyright 2010 Springer.
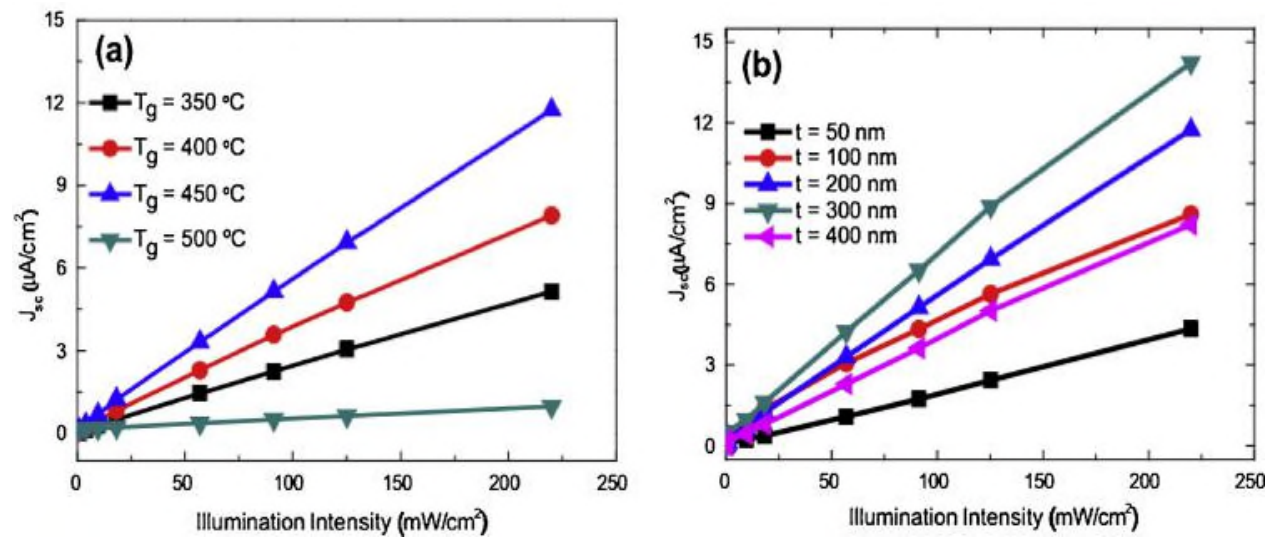

Fig. 3. Average photocurrent versus intensity for (a) 200-nm-thick BiFeO3 films deposited on $\mathrm{Pt} / \mathrm{Ti} / \mathrm{SiO} 2 / \mathrm{Si}(100)$ substrates at various $T_{\mathrm{g}}$ and (b) $\mathrm{BiFeO} 3$ films grown on $\mathrm{Pt} / \mathrm{Ti} / \mathrm{SiO} 2 / \mathrm{Si}(100)$ substrates at $T_{\mathrm{g}}=450^{\circ} \mathrm{C}$ with different BiFeO3 thicknesses [67]. Copyright 2013 Elsevier Ltd. 
(a)
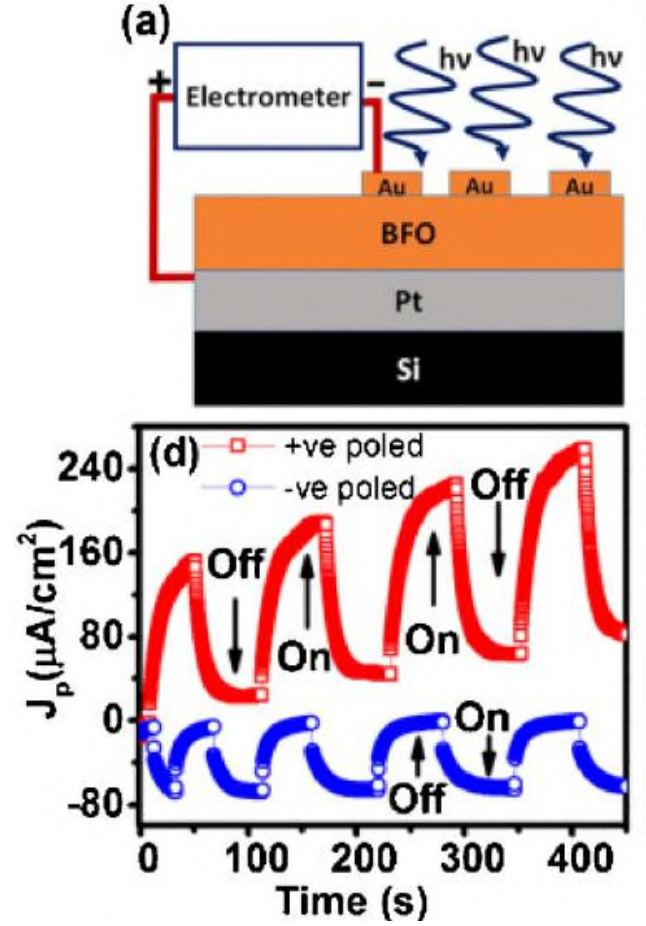
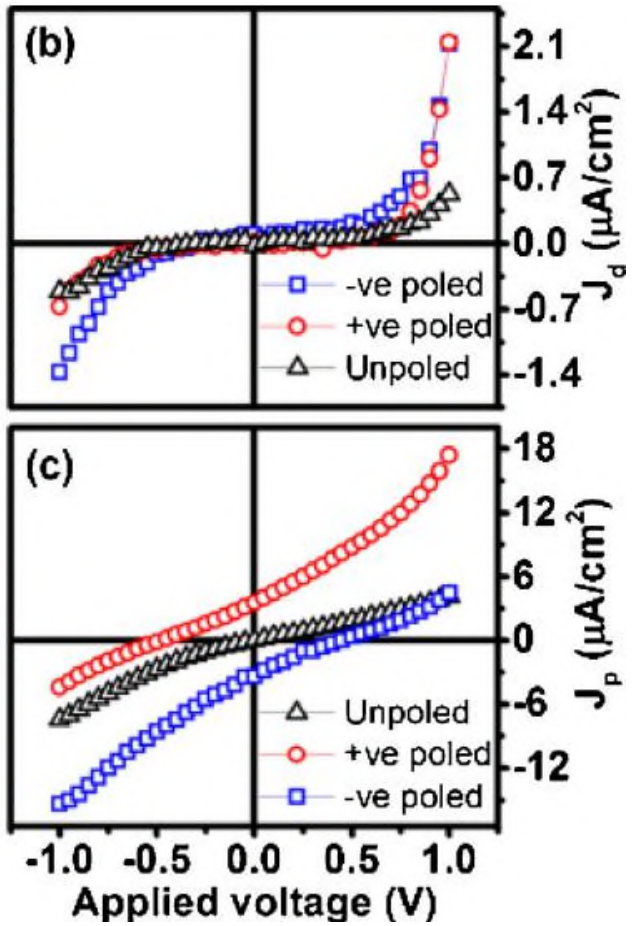

Fig. 4. (a) Schematic drawing showing the geometry used for photovoltaic measurements. (b) Dark current density $J \mathrm{~d}$ as a function of applied voltage for $\mathrm{BiFeO} 3$ measured in the dark. (c) Resultant photocurrent density $J_{\mathrm{p}}$ as a function of applied voltage measured under illumination. (d) ON-OFF curves for positive-and negative-poled states [68]. Copyright 2017 American Institute of Physics.
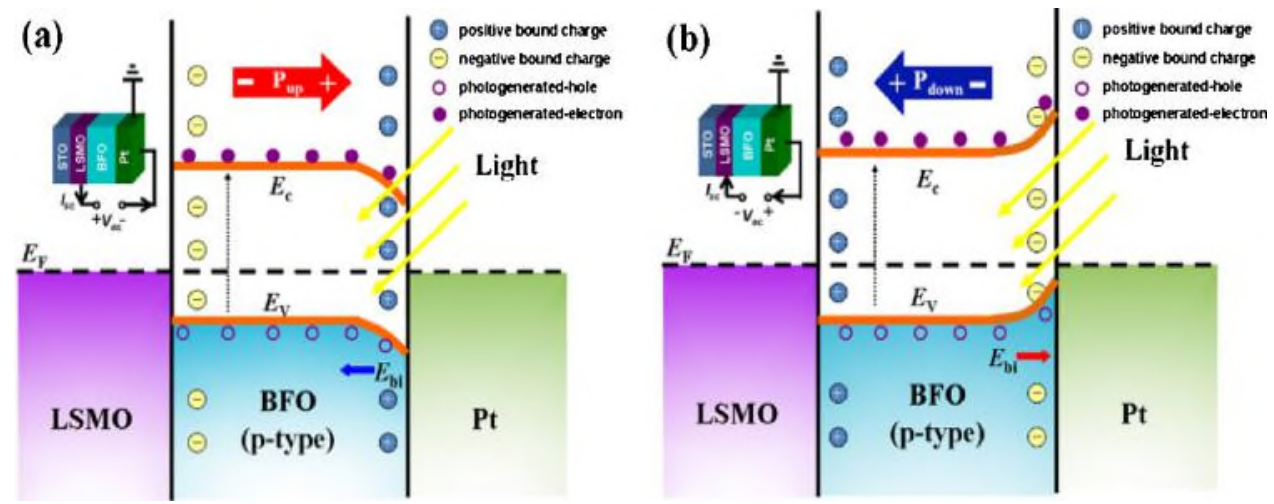

Fig. 5. Schematic energy-band diagrams and operational principle of photovoltaic properties for $\mathrm{Pt} / \mathrm{BiFeO3} / \mathrm{LSMO}$ heterostructure: (a) the upward and (b) downward polarization states of $\mathrm{BiFeO}$. The corresponding insets show the signs and directions of ${ }_{V_{\mathrm{oc}}}{ }^{\text {and }}$ Isc [69]. Copyright 2014 American Institute of Physics. 


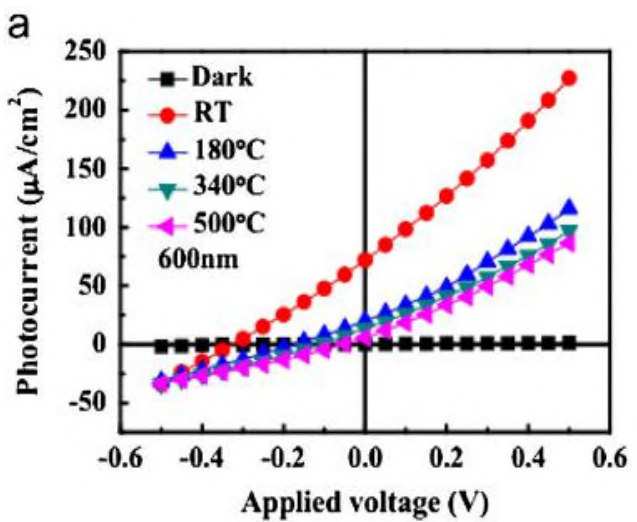

(a)

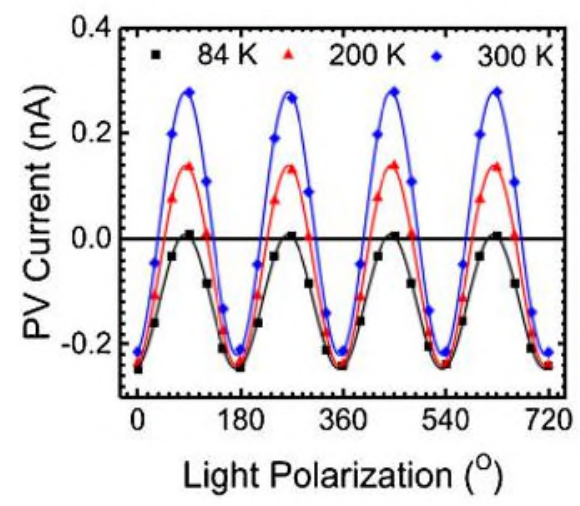

(c)

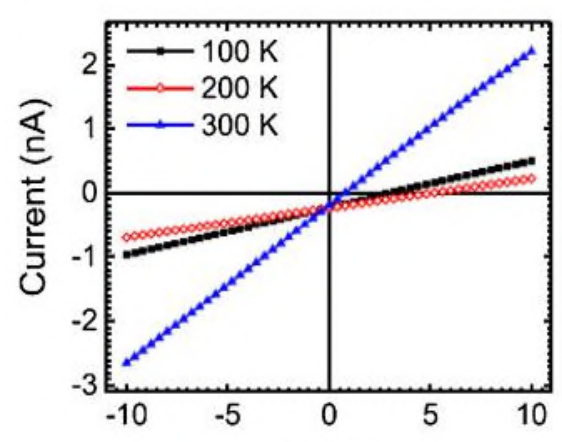

b

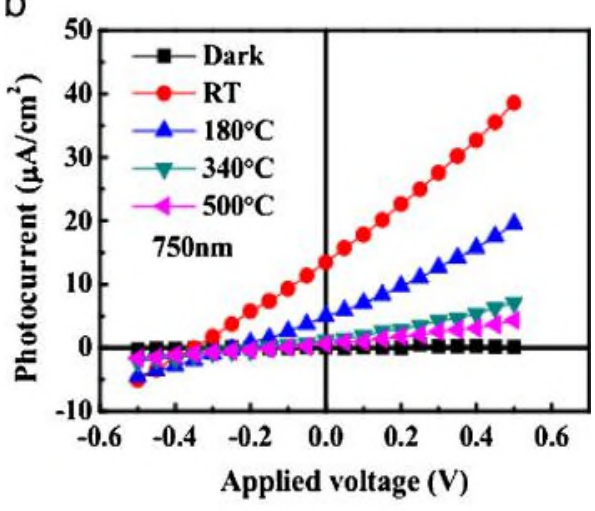

(b)

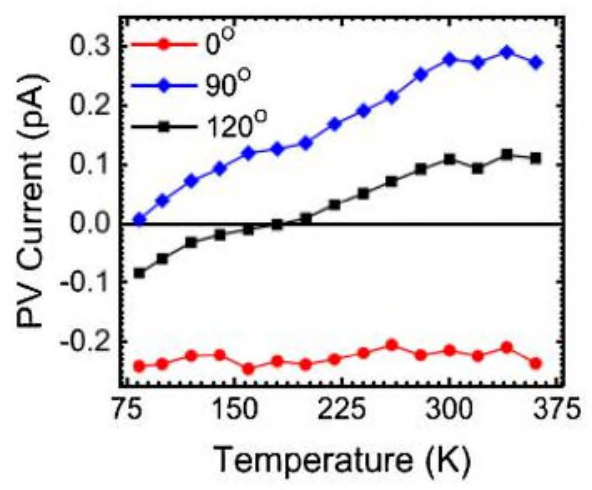

(d)

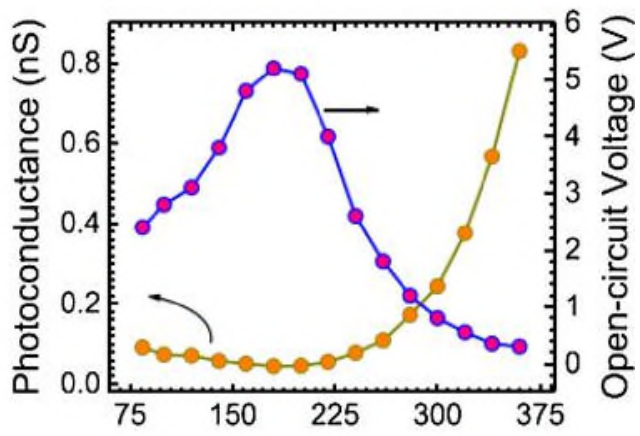

Fig. 6. (a) Photovoltaic effects of $\mathrm{Pt} / \mathrm{BiFeO} 3 / \mathrm{Pt}$ capacitor with 600-nm-thick $\mathrm{BiFeO} 3$ film and (b) photovoltaic effects of $\mathrm{Pt} / \mathrm{BiFeO} / \mathrm{Pt}$ capacitor with 750-nm-thick $\mathrm{BiFeO} 3$ film. The temperatures in the legends are the annealing temperatures of the top $\mathrm{Pt} / \mathrm{BiFeO} 3$ interface $(\mathrm{RT}=$ room temperature $)[70]$. Copyright 2015 Elsevier Ltd.

Fig. 7. Photovoltaic measurements with in-plane electrodes perpendicular to in-plane projection of ferroelectric polarization. (a) Dependence of photovoltaic current on angle between light polarization and in-plane ferro-electric polarization. (b) Temperature dependent photovoltaic current for illumination at different polarization angles. (c) Current-voltage characteristics acquired under illumination with light polarization parallel to the fer-roelectric polarization. (d) Temperature-dependent conductance and open-circuit voltage $V_{0 c}$ under illumination at $405 \mathrm{~nm}$ [71]. Copyright 2017 American Institute of Physics. 


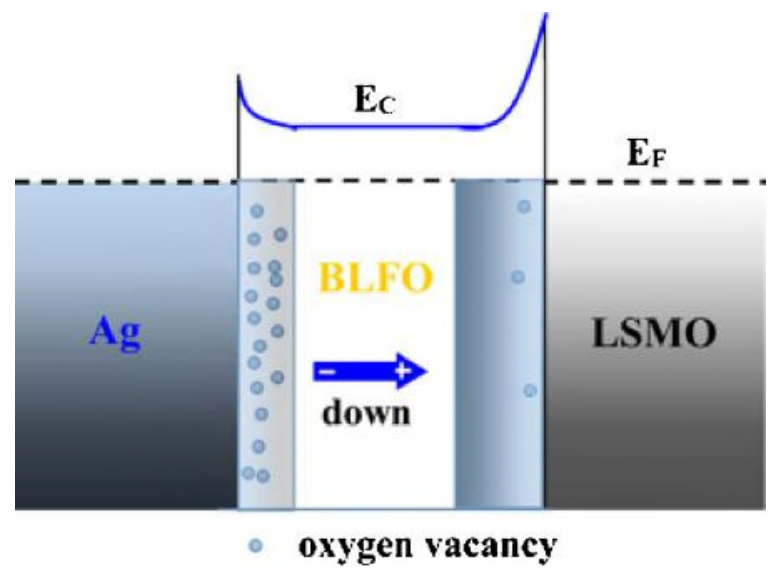

Fig. 8. Schematic energy-band diagrams illustrating the distribution of oxygen vacancies $V O$ for Au/Bi0.9La0.1FeO3/FTO structure. The virgin Bi0.9La0.1FeO3 samples with self-polarization at polarized down [74]. Copyright 2014 Elsevier Ltd.

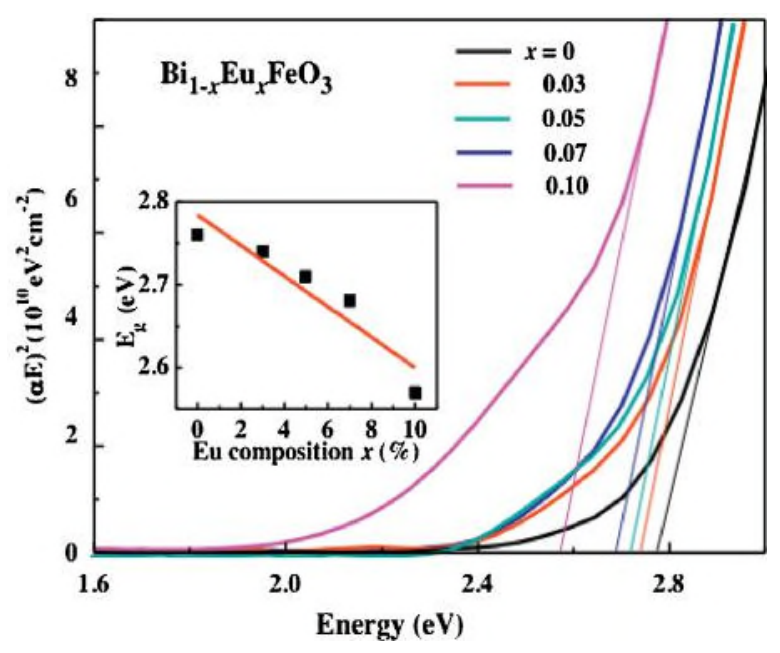

Fig. 10. $(\alpha E)^{2}$ plotted as function of photon energy for $\mathrm{Bi} 1-x \mathrm{Eu} x \mathrm{FeO} 3(x=0,0.03,0.05,0.07$, 0.10) films. The inset shows the variation of the optical band gap of Bi1xEurFeO3 films [78]. Copyright 2014 Elsevier Ltd. 


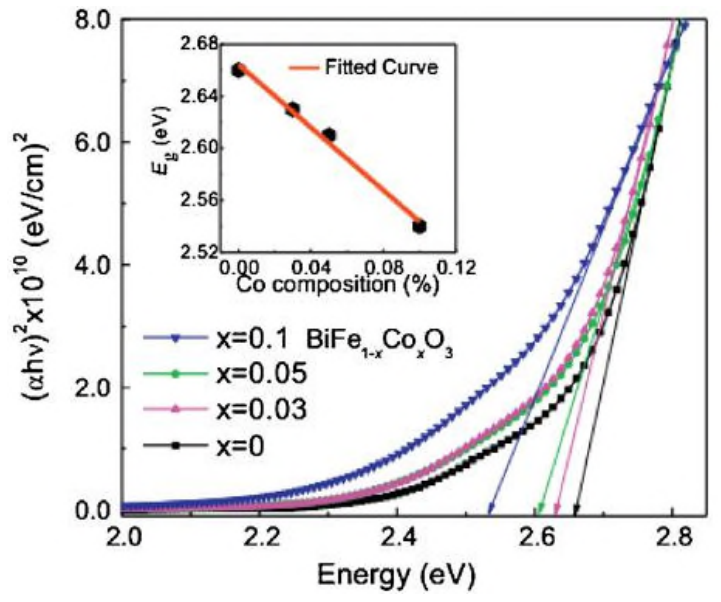

Figure 9

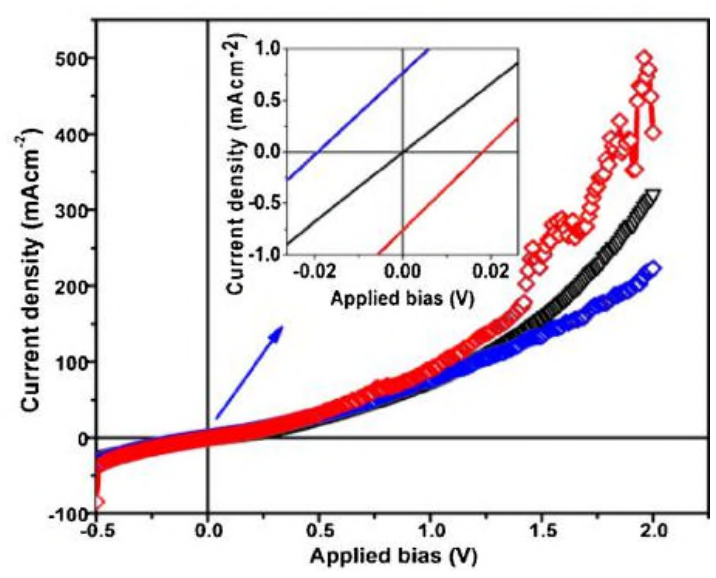

Figure 11

Fig. 9. $(\alpha h v)^{2}$ plotted as function of photon energy for $\mathrm{BiFe} 1-x \mathrm{CoxO} 3(x=0,0.03,0.05,0.1)$ thin films. The inset shows the variation of the optical band gap of $\mathrm{BiFe} 1-x \mathrm{CoxO} 3$ films [77].

Fig. 11. Current density as a function of applied bias voltage for $\mathrm{ZnO}: \mathrm{Al} /$ [Bi0.9La0.1] $\left[\mathrm{Fe}_{0.97} \mathrm{Ti}_{0.02} \mathrm{Zr}_{0.01}\right] \mathrm{O}_{3} / \mathrm{Pt}$ heterostructures under $1 \mathrm{~kW} / \mathrm{m}^{2}$ illumination. The inset shows the region around the origin and identifies the values for $V_{\mathrm{oc}}{ }^{\text {and }}{ }_{\mathrm{Jsc}}$ (red is for negative poling, blue is for positive poling, black is for no poling) [80]. Copyright 2014 American Institute of Physics (For interpretation of the references to colour in this figure legend, the reader is referred to the web version of this article). 


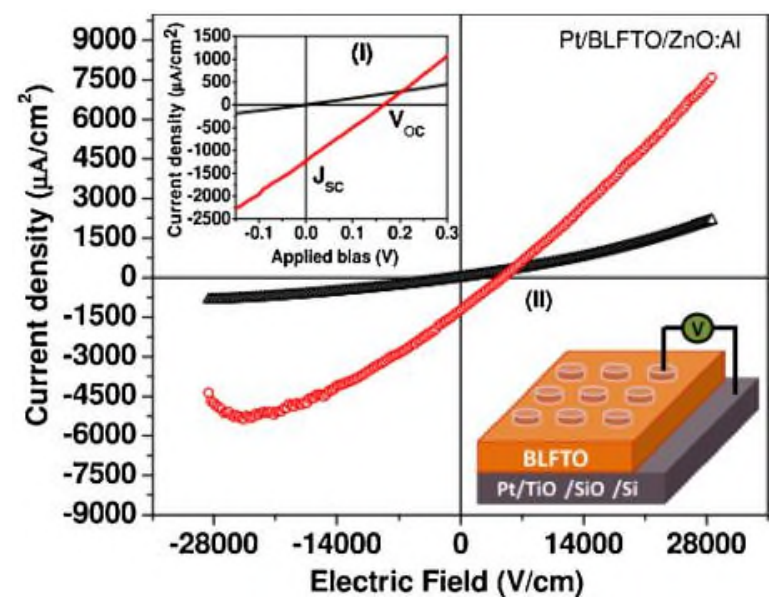

Fig. 12. Current density as a function of applied bias voltage for $\mathrm{Pt} /[\mathrm{Bi} 0.9 \mathrm{La} 0.1]$ [Fe0.97Ta0.03] O3/ZnO:Al heterostructures obtained under $100 \mathrm{~mW} / \mathrm{cm}^{2}$ illumination. The inset shows the region around the origin and identifies the values for $V$ oc and ..lsc (red is for illumination and black is for no illumination). A schematic diagram of a $\mathrm{Pt} /[\mathrm{Bi} 0.9 \mathrm{La} 0.1][\mathrm{Fe} 0.97 \mathrm{Ta} 0.03] \mathrm{O} / \mathrm{ZnO}: \mathrm{Al}$ device appears in the lower right [81]. Copyright 2015 American Institute of Physics (For interpretation of the references to colour in this figure legend, the reader is referred to the web version of this article).

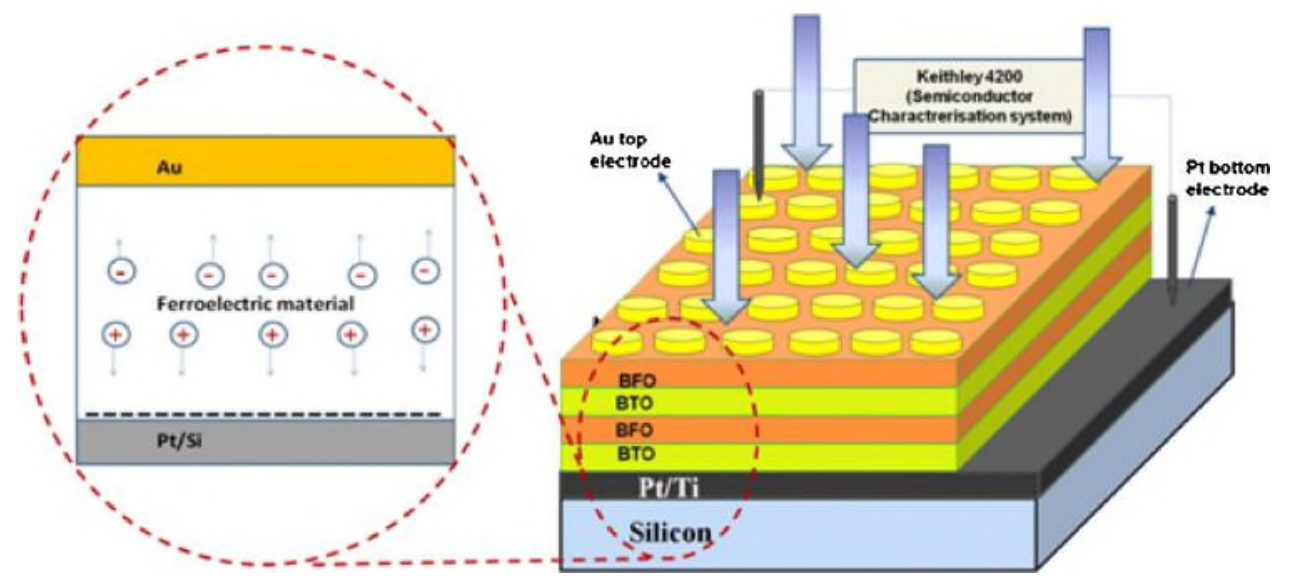

Fig. 13. Schematic diagram depicting separation of charge carriers due to ferroelectric photovoltaic effect after illuminating of $\mathrm{BiFeO} 3 / \mathrm{BaTiO} 3$ multilayered photovoltaic cell [86]. 

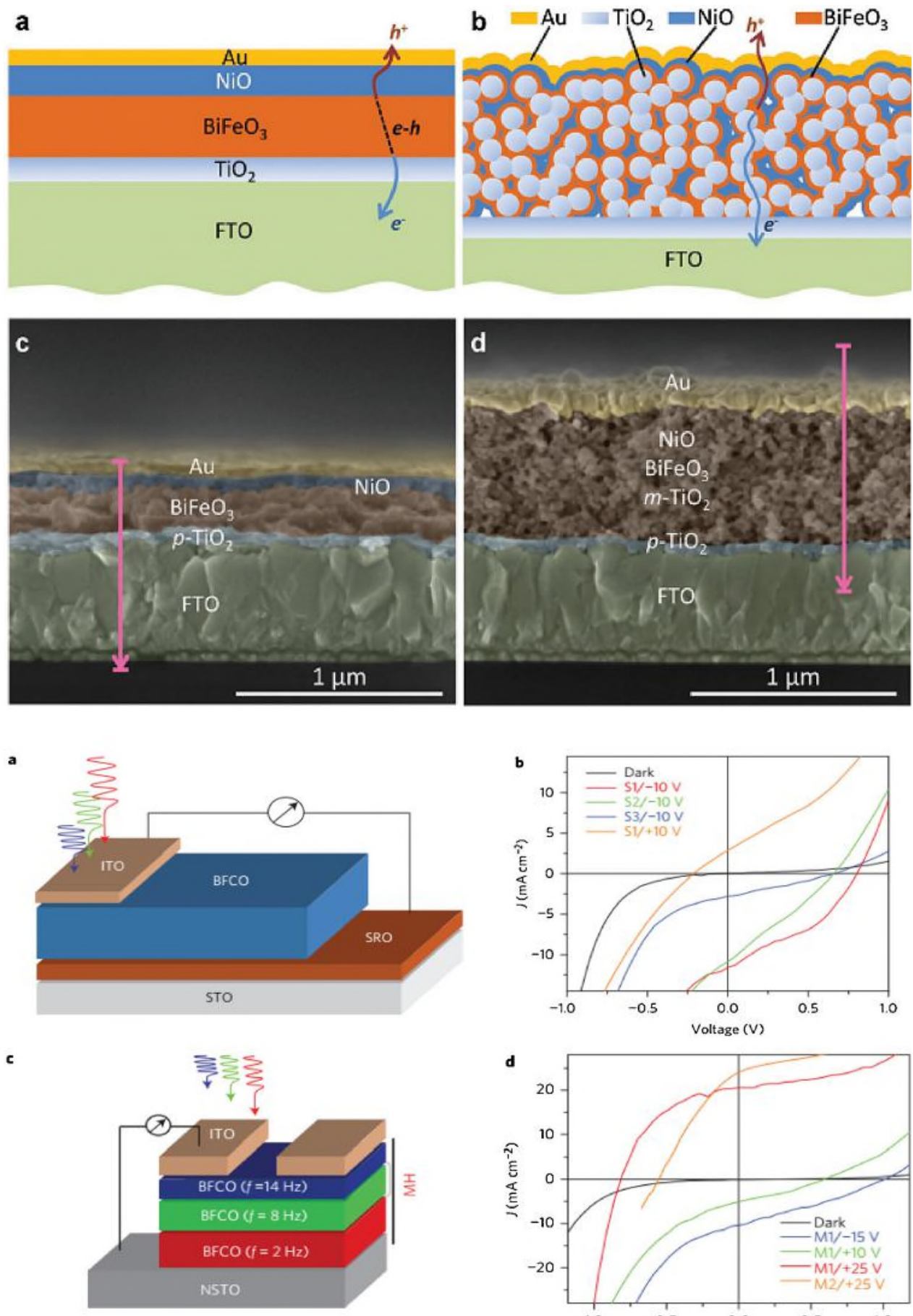

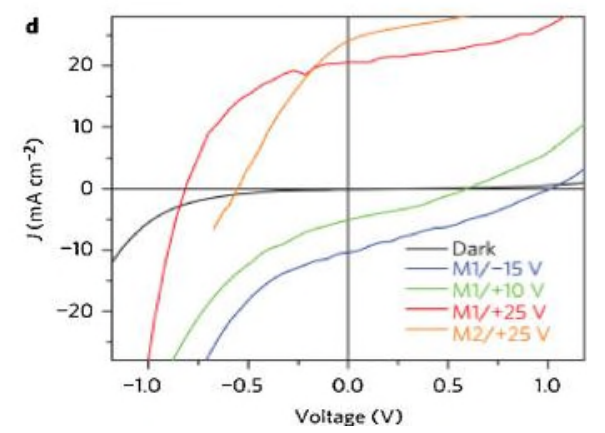

Fig. 14. Schematic device architectures of the a) planar- and b) mesostructured heterojunctions. For the planar-structured heterojunction, only the photocarriers near the $\mathrm{BiFeO} 3 / \mathrm{TiO} 2$ and $\mathrm{BiFeO} 3 / \mathrm{NiO}$ interfaces can be separated and collected by the electrodes. On the contrary, in the mesostructured heterojunctions, the electron-hole pairs generated inside the nanosized $\mathrm{BiFeO} 3$ grains can be effectively separated and injected into the $\mathrm{m}-\mathrm{TiO} 2$ and $\mathrm{NiO}$, and then collected by the electrodes. SEM images of the c) planar-and d) mesostructured heterojunctions [871].

Fig. 15. (a) Layout of tested Bi2FeCrO6 single-layer-based structure. (b) $J-V$ characteristics of $\mathrm{Bi} 2 \mathrm{FeCrO} 6$ single-layer devices under AM $1.5 \quad \mathrm{G}$ illumination. (c) Geometry of tested $\mathrm{Bi} 2 \mathrm{FeCrO} 6$ multilayer structure. (d) $J-V$ characteristics of $\mathrm{Bi} 2 \mathrm{FeCrO} 6$ multilayer devices under AM 1.5 G illumination [891]. 

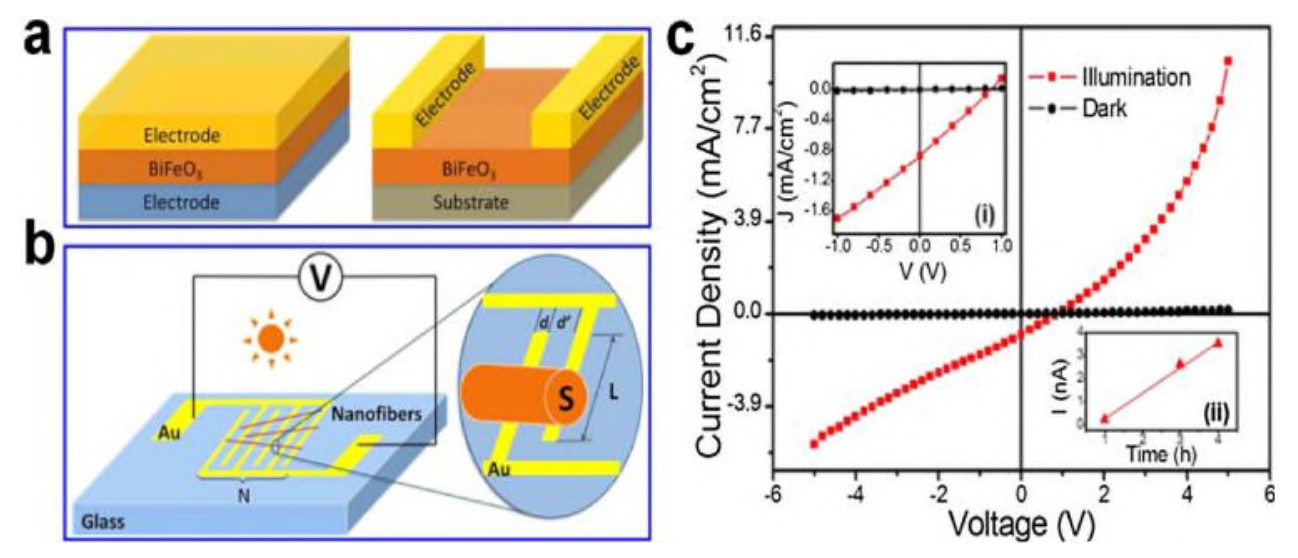

Fig. 16. (a) Schematic illustration of setup for measuring thin-film-based photovoltaic devices. The left panel shows the device in the parallel capacitor configuration. The right panel shows the device with laterally aligned interdigital electrodes. (b) Schematic setup for measuring random BiFeO3 nanofiber-based photovoltaic devices. (c) Photoresponse profile of nanofibers. Inset (i) shows an expanded view of current density near zero bias. Inset (ii) shows the averaged photocurrent after several measurements for deposition times from 1 to $4 \mathrm{~h}$ [94]. Copyright 2015 American Chemical Society. 
Table 1

Summary of performance of reported BiFeO3-based photovoltaic devices.

$\begin{array}{llllll}\text { Device structure } & \text { Voc }(\mathrm{V}) & \mathrm{ISC} & \begin{array}{l}\text { Light intensity } \\ \left(\mathrm{mW} / \mathrm{cm}^{2}\right)\end{array} & \begin{array}{l}\text { Light wavelength } \\ (\mathrm{nm})\end{array} & \begin{array}{l}\text { Efficiency } \\ (\%)\end{array}\end{array}$ $\left(\mu \mathrm{A} / \mathrm{cm}^{2}\right)$

\begin{tabular}{|c|c|c|c|c|c|c|}
\hline ITO/BFO ceramics/Au & & 1.2 & 2 & 373 & & [61] \\
\hline ITO/Ca-doped BFO & 0.42 & 24 & 45.1 & 405 & 0.0072 & [62] \\
\hline ITO/BFO ceramics/Au & & & 0.23 & 405 & 0.002 & [51] \\
\hline ITO/Ba-doped BFO & 0.58 & 34 & 91 & 405 & 0.006 & [63] \\
\hline $\begin{array}{l}\text { ITO/Sr-doped BFO } \\
\text { ceramics/Au }\end{array}$ & & & 125 & 405 & 0.004 & [64] \\
\hline ITO/Sm-doped BFO & & & 1 & 405 & 0.37 & [65] \\
\hline ITO/BFO thin films/Pt & & 14.2 & 220 & 405 & & [67] \\
\hline $\mathrm{Au} / \mathrm{BFO}$ thin films/Pt & 0.47 & 3.82 & 165 & & & [68] \\
\hline $\mathrm{Pt} / \mathrm{BFO}$ thin films/Pt & & & & 404 & 0.011 & [70] \\
\hline $\mathrm{Au} / \mathrm{BFO}$ thin films/Pt & 1.3 & & & sunlight & 0.242 & [28] \\
\hline $\mathrm{Au} / \mathrm{BLFO}$ thin films/LSMO & 0.64 & & & green light & & [76] \\
\hline $\mathrm{Au} / \mathrm{BKFO}$ thin films/FTO & 0.45 & 1.32 & & sunlight & & [79] \\
\hline $\begin{array}{l}\mathrm{ZnO}: \mathrm{Al} / \mathrm{BLFTZO} \text { thin } \\
\text { films/Pt }\end{array}$ & 0.022 & 650 & & & & [80] \\
\hline $\mathrm{Pt} / \mathrm{BLFTO}$ thin films/ZnO:Al & 0.5 & 1350 & & & & [81] \\
\hline $\mathrm{Pt} / \mathrm{BSFHO}$ thin films/LNO & 0.32 & 303 & 100 & sunlight & & [82] \\
\hline $\mathrm{Au} / \mathrm{BCFMO}$ thin films/ITO & 0.25 & 36 & 160 & 405 & & [83] \\
\hline $\mathrm{Au} / \mathrm{BFO}$ thin films $/ \mathrm{BaTiO}_{3} / \mathrm{Pt}$ & 1.43 & 12650 & & & & [86] \\
\hline $\mathrm{ZnO}: \mathrm{Al} / \mathrm{Bi}_{5} \mathrm{FeTi}_{3} \mathrm{O}_{15}$ thin & 0.14 & 16 & & & & [73] \\
\hline $\mathrm{m}-\mathrm{TiO}_{2} / \mathrm{BFO}$ thin films $/ \mathrm{NiO}$ & 0.67 & 510 & 100 & & 0.19 & [87] \\
\hline $\mathrm{ITO} / \mathrm{ZnO} / \mathrm{BFO}$ thin films/Pt & & 340 & & & 0.33 & [10] \\
\hline $\mathrm{ITO} / \mathrm{NiO} / \mathrm{Bi}_{2} \mathrm{FeCrO}_{6}$ thin & 0.53 & 8000 & & & 2 & [88] \\
\hline ITO/ $\mathrm{Bi}_{2} \mathrm{FeCrO}_{6}$ multilayer thin & 0.84 & 20600 & & & 8.1 & [89] \\
\hline Ag/Pr-doped BFO NTs/Ag & 0.21 & & 10 & white-light & 0.5 & [95] \\
\hline
\end{tabular}


2018-10-09

\section{Bismuth ferrite materials for solar cells: Current status and prospects}

Chen, Guang

Elsevier

Guang Chen, Jian Chen, Weijie Pei, et al., Bismuth ferrite materials for solar cells: Current status and prospects. Materials Research Bulletin, Volume 110, February 2019, Pages 39-49 https://doi.org/10.1016/j.materresbull.2018.10.011

Downloaded from Cranfield Library Services E-Repository 